\title{
PROMOTING SOCIAL VALUES IN EGYPTIAN MARKETS PLACES
}

\section{Amna Waz Amgad Aly", Aly Mohamed El Husseiny}

Department of Architecture, Faculty of Engineering, Minia University, 61519 Minia, Egypt

* Correspondence: amna.amgad@mu.edu.eg; Tel: + 201124577856; Fax: +20 86236674

\section{Article information}

Received: 10 February 2020

Revised: 2 March 2020

Accepted: 3 March 2020

\section{Key words}

Egyptian Markets

Social Marketing Orientation

Shopper behavior

Activity Associated with Shopping

\begin{abstract}
The Egyptian urban markets began to give up their social and cultural role for their society, especially in the popular markets.

The research aims to explore the social role and the added value of shopping performed by places of trade activity in Egypt. Then the researcher learns the points of promoting the activities associated with shopping. The urban markets will perform their developmental social role in compatible with the social orientation of marketing.

The research followed the methodology of studying the concept of social marketing orientation. The Orientation aims to support the society and create value for markets. The social trend directed the research to observe patterns of activities associated with shopping in Egypt and to study the shopper's satisfaction. Then the researcher conducted interviews and a questionnaire for a random sample of 109 Egyptian shoppers (The sample corresponds to its characteristics with the Egyptian society, the sample size is statistically acceptable with the inferential and non-parametric tests used). Then the results were analyzed statistically with the SPSS program. The researcher concludes the current state of the rate of interaction, the reasons for attracting the study sample to the activities associated with the Egyptian markets, And the level of individual satisfaction with the Egyptian market.

The research conducted that the social role in the Egyptian market is weak now, and suggested points that support the social orientation of marketing. The research recommends to correct the social orientation path of urban markets, and to create active social spaces in the markets. The spaces allow cultural development interaction between people. An organized plan must be devised for the patterns of cultural development activities (Research aims to confirm it in the markets) which suit the target marketer. The activity contributes to directing the members of society towards the needs of their country.
\end{abstract}

\section{Introduction}

In the context of the contemporary life, electronic shopping began crowding traditional shopping; it threats the human presence in trade markets of all kinds. In other words, what would shopping spaces look like in the near future; If It is deserted by humans? Human interaction in public shopping areas is a value, which deserves to keep conserving. The social solidarity characterizes the nature of the Egyptian communities. In previous eras, The Egyptian market was characterized by performing roles accompanying trade activity. Where, the pattern of associated activity with markets and its impact varied from time to time. The Egyptian market was the place of daily events on the cultural and social level in the Islamic era [1]. The trade street was planned in the Islamic era (639AD: 1850AD) with a specific width, refractive path, usually winding and insufficient for the presence of any activities. But the path creates an arena for each period to contain an activity [2].

Some of the accompanying activities began to withdraw from the markets, especially after the Industrial Revolution. So, the manufacturing goods were separated from the markets, and stores focused on selling their goods in order to increase profits. The financial aspect dominated the market and gradually began to lose its social life [3] \& [4].

E-market has emerged due to technological advances and the revolution in communications. The interaction between the marketer and the shopper is taking place during the virtual reality, and this causes lacking interactive activities accompanying the trade [5] \& [6]. As seemed in (Figure 1).

Questions have arisen about the potential of marketing to facing the society problems (population explosion - poverty - famine ....) [8], the shortcomings in social services and the ability of markets to achieve the shopper needs, the taking into account the community's interest and the achieving social welfare in the long run for society.

This resulted in the emergence of social responsibility for the marketing activity to maintain a balance between the interests of the shopper, society and the commercial entity [9] \& [10]. Peter Drucker mentioned the social orientation of marketing in 1957. The social marketing is the dynamic operations of commercial entities, which integrate their products with the goals and values of society [11] \& [12]. 


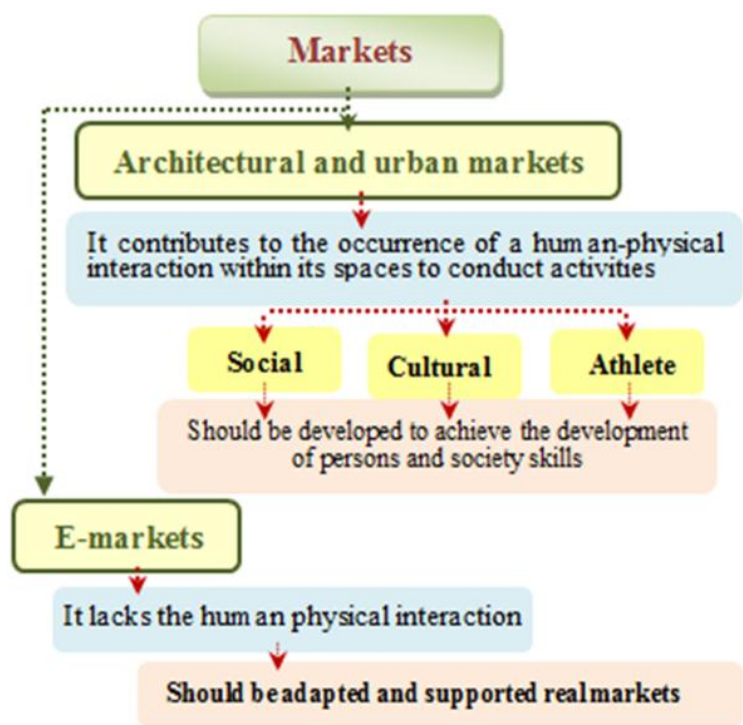

Figure 1: Market patterns are categorized according to the variables types of presence and effects on human interaction [7]

\subsection{The Research Problematic}

The current Egyptian markets have lacked their social and cultural role. The markets were a place for social interaction, recreation and production, along with trade activity in ancient times. Some the current markets do not have activities associated with shopping, and some have non-development consumer activities.

Now, The Egyptian market has appeared purposefully for financial gain only. The markets did not consider any development aspect or local economic dimension. So, the paper looks for enhancing a humanistic approach by linking the shopping with the society's culture development.

\subsection{Scope of research}

Purchasing behavior is influenced by many factors, which are leading to the success of the market. These factors were divided into factors specific to the marketer, factors specific to the market, factors specific to marketing and factors specific to the commodity [17].

All of these factors will be studied from the shopper's vision, where the paper focuses on achieving the development of persons and society skills by linking the shopping with the society's culture development.

The shopper's vision shows the humanity elements that influence the design of the markets, whether they are demographically (gender and age groups), cultural, social, economic (income - spending rate ....) or buying habits (the shoppers' accustom behaviors during the shopping) [6].

The main issue for the researches is the social and human interest. The research will focus on the preferences of shoppers (the most important member of the market), and factors specific to the market within the framework of complementary activities (effect on the attraction and behavior of individuals in the market). That may lead to a humanistic market and suit the local society.

\subsection{The Research purpose}

The research explored the extent to which markets play a social role; the style and rate of the Egyptian shopper interaction with the accompanying activities within the Egyptian urban markets was observed, the shopper's attitudes and behaviors was determined to know how can enhance the associated activities with shopping and real human interactions. At the end, the supporting points for the social role of the Egyptian urban markets with a developmental manner are reached.

\subsection{Research methodology}

The research based on the following methodological procedures:

\section{- Inductive deductive approach:}

The research adapted the concept of marketing social orientation; the orientation aims to support the interest of society, and develop the values of markets. A study of the social orientation concept was reached to the possibility of monitoring the extent to which markets provide their social role by observing activities associated with shopping and identifying the level of shopper satisfaction.

The social orientation directed the research to observe the accompanying activity in the Egyptian market, and identify the shopper's satisfaction. The questionnaire tool was chosen to measure the satisfaction of a sample of Egyptian shoppers with Egyptian markets.

\section{- An exploratory and analytical approach:}

The research observed the behavior of the Egyptian shopper related to the activities associated with shopping and the level of satisfaction with the Egyptian markets. Observing was done through field interviews and filling out a questionnaire for a sample of Egyptian shoppers.

The study sample was tested statistically in terms of personal characteristics of the sample members (gender- age- number of family members) with the origin of the Egyptian community, to ensure the validity of circulating the results of the questionnaire. The research has adopted the SPSS program to find relationships between the societal shopper groups and study areas.

\section{- Qualitative inductive approach:}

The research adopted, when setting the study conclusions (Points were suggested to support the social role of the Egyptian markets) on the relationships that were observed through the questionnaire form, observations of field visits to Egyptian markets, and the quotation from the directives of theories of social change and theories of behavior change. These theories contain scientific methods that can be used to make deliberate 
changes in social reality. Thus, social marketing orientation goals can be achieved. As seemed in (Figure 2).

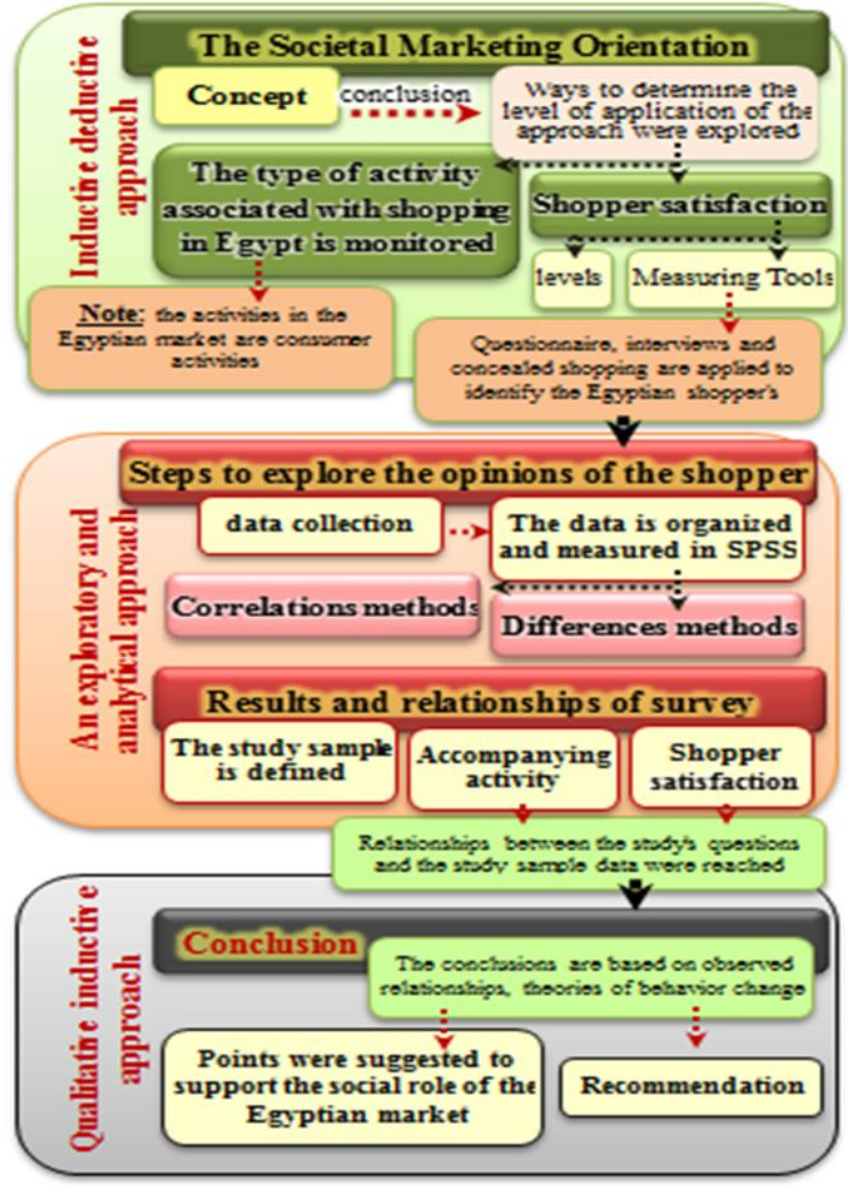

Figure 2: Explain the structure of research [7].

\section{Definition of Social Marketing}

The concept of social marketing focuses on the interest, welfare of society and support the prevailing values in society before any other benefit, Profit is not the only goal of the marketer [13].

This approach aims to enhance the positive impact of trade activity, reduce the negative impact on society, and provide more goods and services. This is in proportion to the rise in the standard of living for individuals [3].

Social marketing often seeks to bring about changes in the values, ideas, and behaviors of members of society or a target group. It can also be used to persuade a segment of society to serve in order to achieve developmental, economic, or political goals [8]. As seemed in (Figure 3).

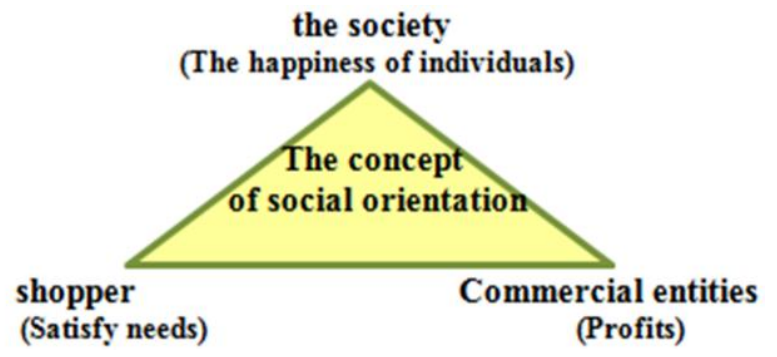

Figure 3: The pillars of the social concept of marketing [14] .p.21
This trend was reflected in the form of markets, as markets focused on the moral or psychological aspect of the shopper. So, areas were introduced to allow for social communication, and to document the relationship between shopping\& entertainment or any supplementary activity. The complementary activity is characterized by encouraging the shopper to spend the largest period in the market, and achieving the highest level of shopper satisfaction[15]. Cairo Festival Mall in New Cairo gives shoppers the opportunity to enjoy the elements of water and outer space as a kind of attraction for shoppers. It Creates spaces that allow for social communication. As seemed in (Figure 4).

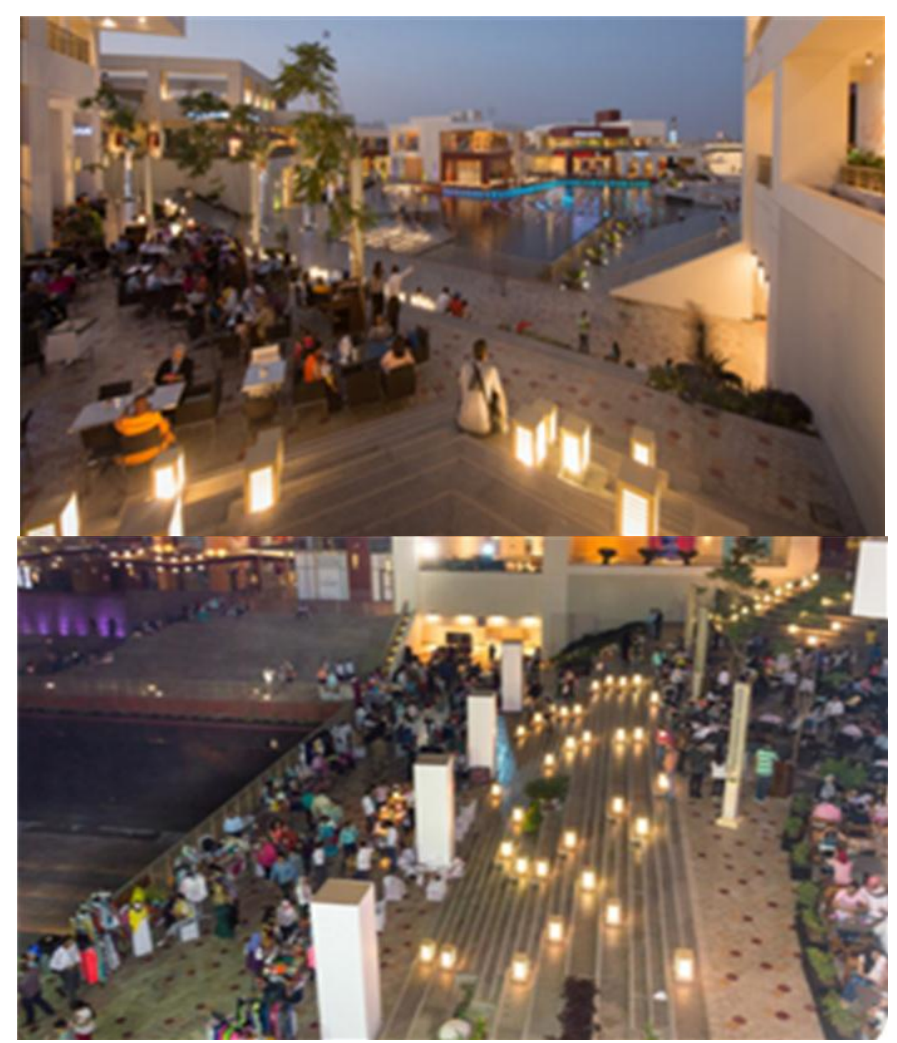

Figure 4: Cairo Festival Mall in New Cairo Creates spaces that allow for social communication [16].

The social trend produced the entertainment center style in the modern era, especially after the competition has increased between the downtown markets and the markets outside the city. Some markets have been associated with celebrations and festivals as a kind of attractive marketing policy for the shopper [4]. The courtyard was considered as a distinctive sign for any mall. This space contained statues, industrial animal parks, and used for fashion shows, music, play areas, cafe, and restaurants. The social trend has produced shoppers who go shopping for entertainment, and some shoppers may offer entertainment on shopping [5].

The social orientation directed the research to observe patterns of activity associated in the Egyptian market, and identify satisfaction. Because the trend was built on attracting the shopper to the markets by achieving the highest satisfaction rate for the shopper. 
2.1. Exploration the actual accompanying activities in the Egyptian markets

The researcher visited and interacted with a number of Egyptian markets to observe the behavior of shoppers regarding activities associated with shopping. The marketer exploits this trend in adding complementary activities in the markets that allow social communication and entertainment (caferestaurants- Cinema...), which encourages the shopper to spend more time in the market. However, Egyptian Markets neglected the developmental dimension of society by the activities associated with shopping, but emphasized the culture of consumption that is harmful to society. As seemed in (Figure 5).

\subsection{Shopper satisfaction in different markets}

Shopper satisfaction is the compatibility between the perceived performance of a shopping experience and the shopper's previous expectations; It is a measure of market success. Satisfaction is achieved by generating a positive feeling after shopping. The shopper is satisfied by comparing the performance or evaluation of the level of his/ her shopping trip with the expectations of the shopper before the trip [17]. As seemed in (Figure 6).

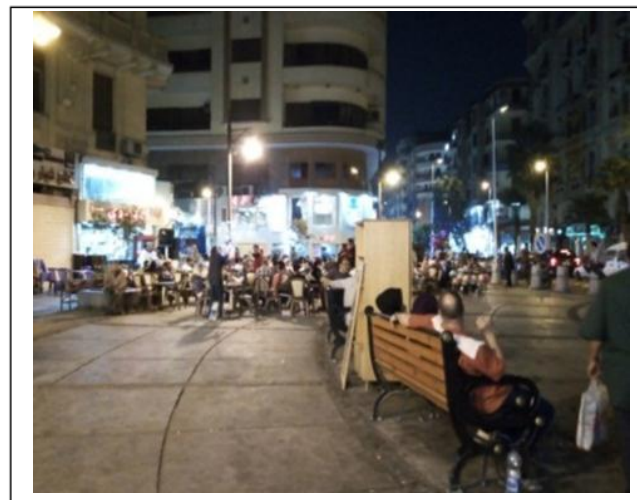

5[a]. Ahmed Orabi Square at the intersection with Mohamed El Alfi Street, in cairo

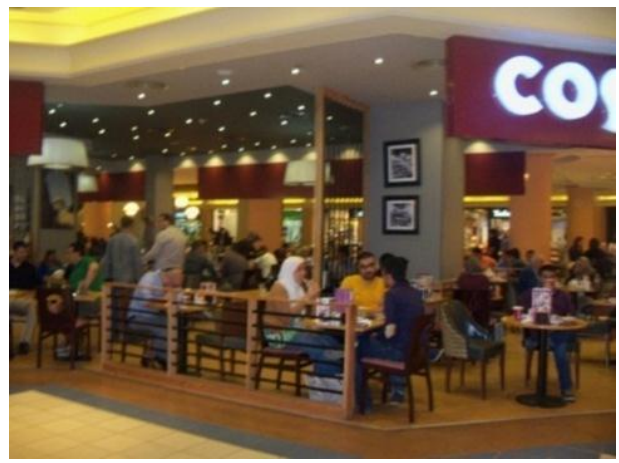

5[d]. City Stars mall, in Nasr city

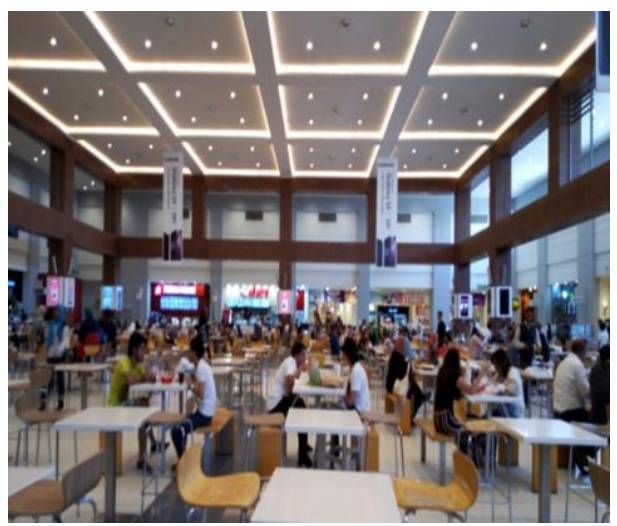

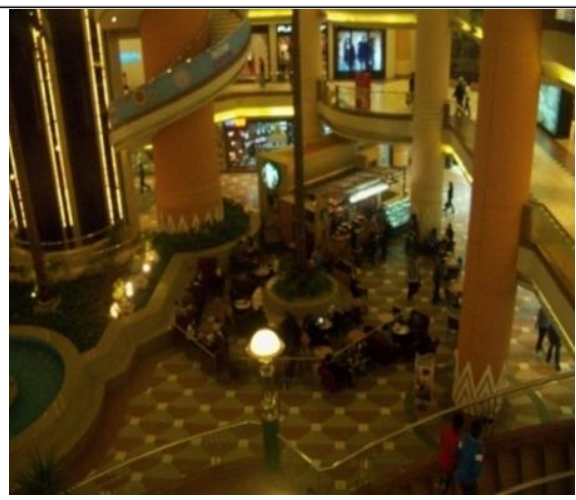

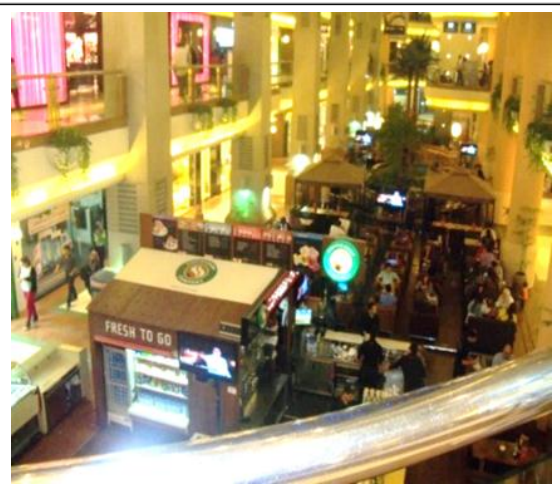

5[b-c]. City Stars mall Atirum, in Nasr city



5[e]. Ahmed Maher Street, in Minia
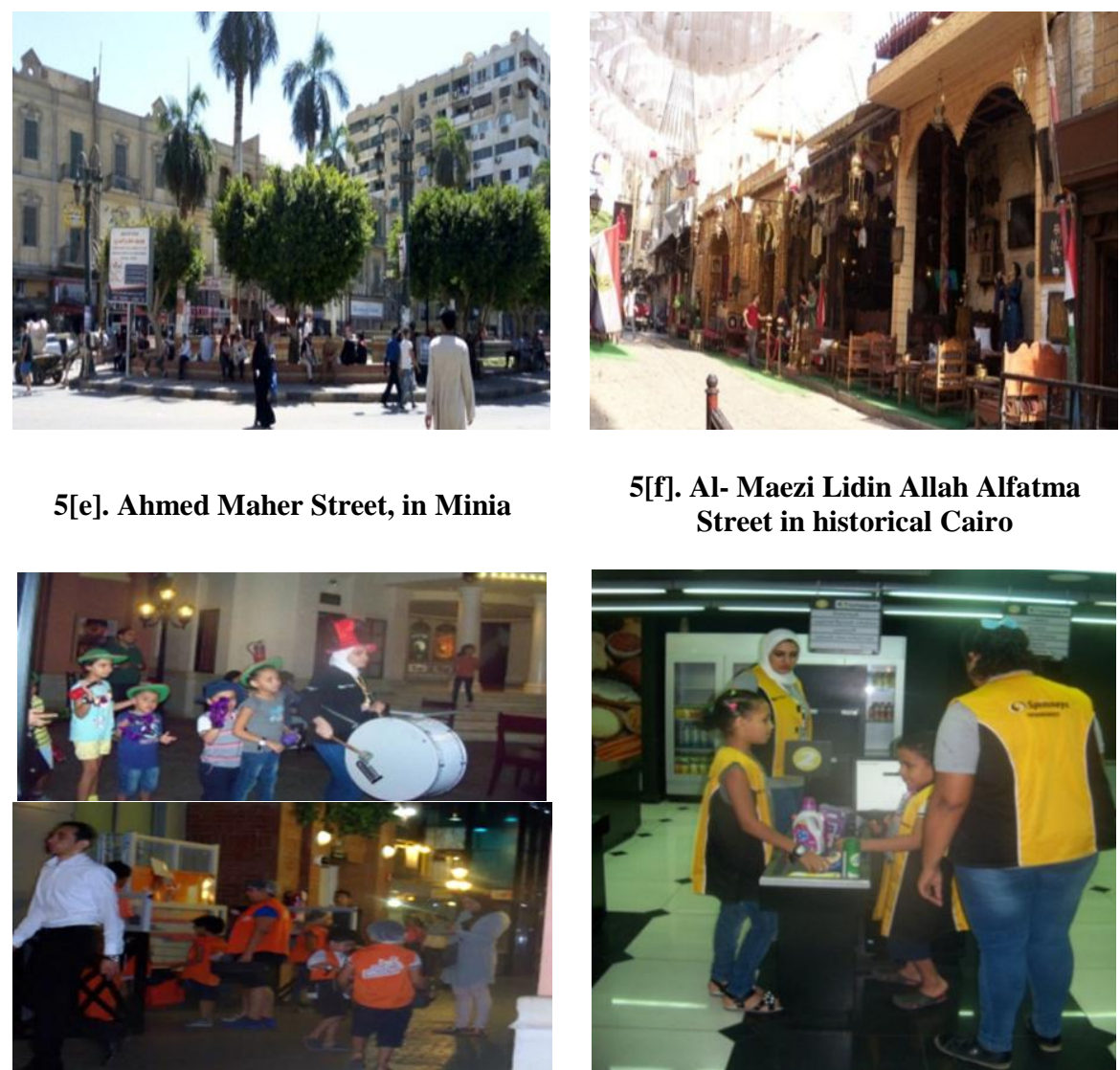

5[f]. Al- Maezi Lidin Allah Alfatma Street in historical Cairo

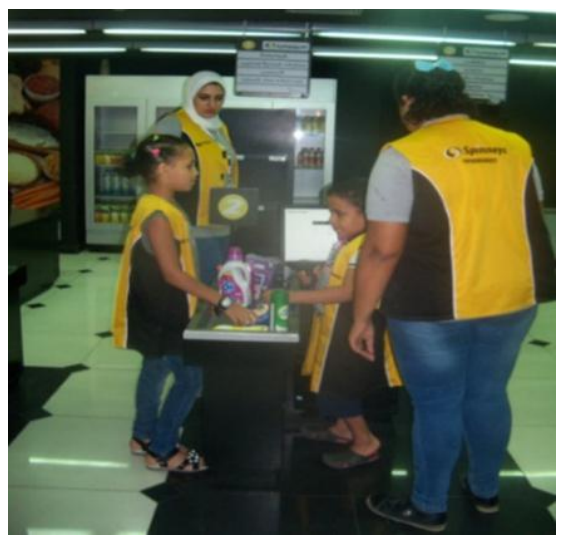

5[g-h-i-j]. Cairo Festival Mall, in New Cairo

Figure 5: The activities associated with shopping were observed in a number of Egyptian markets [7]. 


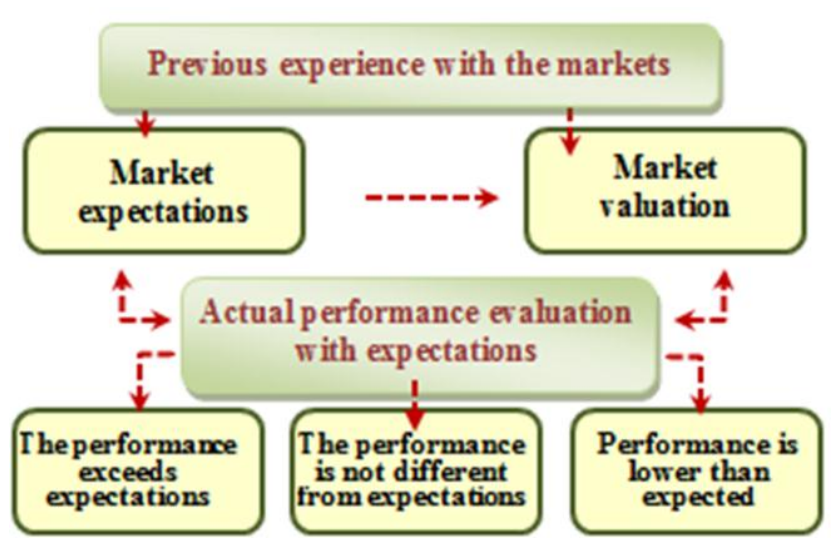

Figure 6: Shopper satisfaction through the markets [9]. P.119

\section{There are three levels of satisfaction:}

A. The first level: the experience is better than expected, so the shopper is satisfied and very happy with his/ her trip.

B. The second level: the experience level equals the expectations, so the shopper is satisfied with his trip.

C. The third level: The experience level is less than expected, so the shopper is not satisfied with his/ her trip.

The level of shopper satisfaction can be measured by the following tools:

A. The questionnaire: The researcher asks questions about a sample of shoppers to measure the frequency of the market and the reason for the rate.

B. Hidden shopping: The business entity appoints individuals who act as shoppers. They report to the management on the strengths and weaknesses observed during the buying process from the business entity itself or from its competitors.

C. Suggestions and Complaints: The business entity received the shopper's complaints and suggestions through traditional facilities or modern communication technologies.

D. Marketing Share: The percentage of the store's sales of a good during a certain period of time is calculated from the total sales of the same commodity in the market. Increasing this percentage indicates the progress of this commercial entity, expanding its market base and increasing its profits. The marketing share is measured from the following formula[9]:

Marketing Share $=\frac{\text { specified time period in commercial entity sales }}{\text { period in industry sales }} \times 100$

The research will rely on the questionnaire and suggestions to measure the shopper's satisfaction with their applicability. These methods provide the opportunity for communication between the researcher and the shopper. It provides an opportunity to learn about the shopper's desires, nature of their behavior. The results of the questionnaire can be analyzed statistically to reach clear relationships.
3. Steps for exploring the Egyptian shopper opinions (Introducing the applied study)

The field study is concerned with observing the behavior of the Egyptian shopper with complementary activities in the markets. The research measures the level of satisfaction of the study sample about the Egyptian markets.

\subsection{The data collection stage to explore the shopper's satisfaction and interactions with the associated activities}

The research relied on collecting data on primary sources [data the researcher collects by himself]. It applied a targeted interview method between the researcher and a random sample of shoppers in market space. Part of the interview was codified [asking specific questions that require accurate answers], and an open part to give the study sample an opportunity to interact and express their opinions, so the interactions, expressions, and reactions of the study sample are monitored\& understood during the interview.

The research presented a list of a questionnaire consisting of four parts. The first three pivots came in the form of closed, multiple-choice questions [most of them being five-fold] to facilitate the evaluation and analysis of results. The classification of the study axes is as follows: -

\subsubsection{The first axis: personal data for the individuals in the questionnaire sample (questions 1: 6):}

The first axis is specialized in collecting personal data for the individuals in the questionnaire sample, which are demographic data. The results of the questionnaire will be analyzed and classified on personal data. The previous studies observed the impact of demographics on the shopper's behavior, which requires identifying the behaviors of each category to determine their needs in the market.

\subsubsection{The second axis: associated Activities with shopping (questions from 7: 11)}

The axis observes the level and manner of the shopper dealing with the non-traded elements in the market. Because the accompanying activities are among the most important elements of attraction in the markets, and to determine the rates of behavior of the Egyptian shopper activity within the market (purchasing behavior only- entertainment buying behaviorbuying entertainment behavior).

\subsubsection{The third axis: Satisfaction with the markets (questions from 12: 18)}

This axis deduces the level of satisfaction of the Egyptian shopper, with the places of trade activity that he visits. This was done with a direct question and indirect questions (The market presence to the shopper and the reasons for the presence rate are known). 


\subsubsection{The fourth axis: The suggestions and comments of the shopper about the markets}

This part consists of an open question. The research combines the opinions, feelings, and opinions of the study sample on the Egyptian markets. The open question also enables to obtain unexpected answers. As seemed in (Figure 7).

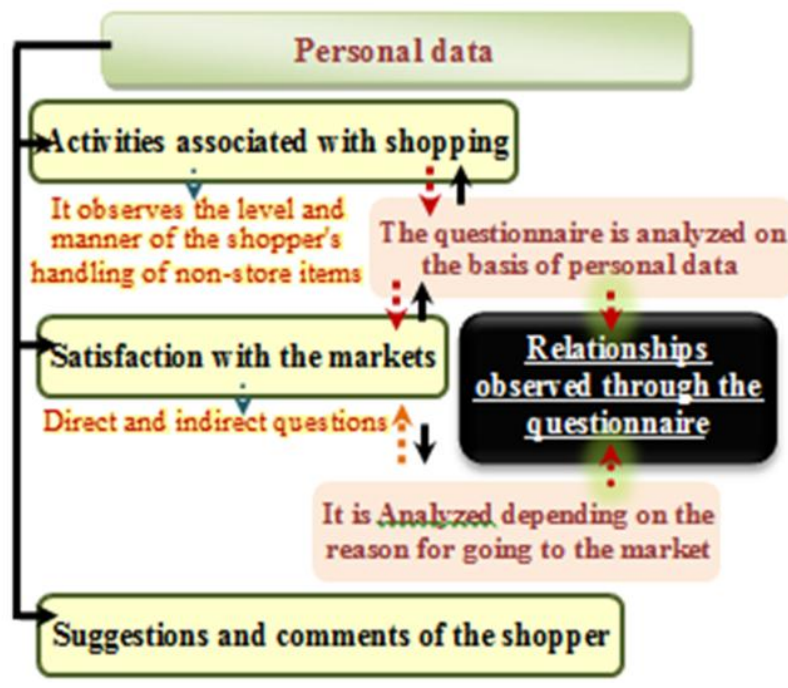

Figure 7: Elements of the survey study and the desired goal of each part [7].

A portion of the questionnaire forms were filled in during the interviews, so that the questionnaire form is the legal part organized for the interview. The search used Google forms to publish questionnaires online by logging on at https://www.google.com/intl/en_eg/forms/abouts/ which facilitates the process of filling out the questionnaire via social networks.

\subsection{Data organization \& statically analyses:}

The research used the Statistical package for social sciences (SPSS) program to organize the raw data for the results of the questionnaire; The research relied on Non parametric Inferential Statistics. The pattern of inferential statistics depends on the choice of a small random sample from a population [the Republic of Egypt]. The research is applied to the random sample, and the results and conclusions we obtain can be generalized to the whole society.

The Non parametric method fits with qualitative data (nominalordinal) in the questionnaire. Non-parameter statistics tests are easy to interpret, and there are no specific conditions for their implementation. The applied study was based on the following statistical methods: -

\subsubsection{Correlations methods}

Are used to detect the two variables that change together at the same time. The aim of this test is to determine the strength and quality of the relationship that links the two variables. The correlation coefficient value ranges from 1 to -1 , and the relationship between the two variables is explained according to the correlation coefficient value. The correlation is invariant when the correlation coefficient value is positive, and inverse when the correlation coefficient value is negative [18]. Spearman's coefficient of rank correlation and Kendall Correlation Coefficient were found between the questions of the rank of personal data and the questionnaire ranks or open (Individuals can choose more than one answer to the same question). As seemed in (Figure 8) \& (Table 1).

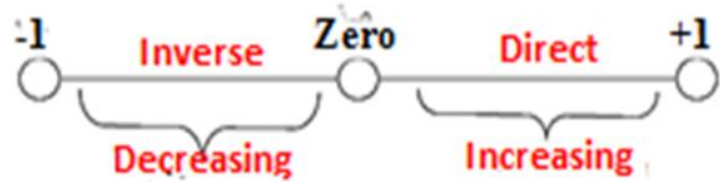

Figure 8: The correlation coefficient limits and the meaning of the relationship.

The significance of correlation coefficient was tested with a level of significance of $5 \%$ (confirmation of test result by $95 \%$ ). Where statisticians agreed that the ratio 0.05 is the highest degree of doubt that can be accepted, the relationship in the sample can be generalized to the indigenous community. The statistical assumptions are formulated as follows:

\section{- Null Hypothesis $\mathbf{H}_{0}$ :}

The linear correlation coefficient between the two variables is equal to zero $(\rho=0)$. This means that the association is not significant. This assumption is achieved when the value of the statistical significance level is greater than 0.05 .

\section{- Alternative Hypothesis H1:}

The linear correlation coefficient between the two variables is nonzero $(\rho \neq 0)$. This means that the association is significant. This assumption is achieved when the value of the significance level is less than 0.05 .

\subsubsection{Differences methods}

Reveal the extent of homogeneity of samples and the extent of their affiliation to one original (such as revealing the differences between male and female tendencies). The statistical assumptions are formulated as follows:

\section{- Null Hypothesis $\mathbf{H}_{0}$ :}

It means that there are no significant differences between groups. Null hypothesis is accepted when the value of the Significance Level is greater than 0.05 .

\section{- Alternative Hypothesis H1:}

It means that there are significant differences between groups. Alternative hypothesis is accepted when the value of the Significance Level is less than 0.05 .

The research applied methods of verifying differences in the pattern of one - sample. The study was relied on as a test Chi - 
square, which is inferred if the observation distribution different or compatible with the theoretical expected. The Chi-square test was used with the Cross tabs command to study the differences between the directions of the study sample according to personal data. Chi-square test is concerned with the nominal scale (available in number of questions). As seemed in (Table 1).

Table 1: Equations of correlation coefficient and difference test $[19,20]$

\begin{tabular}{lc}
\hline & \multicolumn{1}{c}{ equation } \\
\hline $\begin{array}{l}\text { Spearman } \\
\text { correlation } \\
\text { coefficient } \\
\text { equation }\end{array}$ & \multicolumn{1}{c}{ d: The difference between the ranks of the two } \\
& nariables \\
& n: Sample pairs number
\end{tabular}

The Chi-square test law used in the application

$$
\mathrm{x}^{2}=\sum_{i=1}^{k} \frac{\left[\boldsymbol{O}_{i}-E_{i}\right]^{2}}{E_{i}}
$$

$\mathrm{X}^{2}$ : The value of the area below the curve at the right end, which means the number of final observations after the merge

$\mathrm{O}_{\mathrm{i}}$ : Viewer repetition

$\mathrm{E}_{\mathrm{i}}$ Expected recurrence:[The second variable individuals number $\mathrm{x}$ The first variable individuals number] / [The study is for the kidney sample size]

\section{Results and relationships of the themes of the survey study}

This section presents the results of the questionnaire form after applying the appropriate statistical methods.

\subsection{The study sample is defined in the axis of personal data \& the conformity of its community is revealed:}

The random sample consisted of 109 individuals from the Egyptian society. It is a small sample attributed to its original community, but it is statistically acceptable due to the large size of the original community. The drawn sample covered most of the Egyptian society, but there were differences between the study sample categories according to the significance level of the Chi-Square test which was less than 0.05. There are also differences between the proportions of the groups of the study sample and the study community according to their personal characteristics. This difference is considered acceptable from the point of the previous theoretical studies view. Where there are categories that are more interested and influenced by shopping activity. The research applied statistical tests to ensure that the study sample was accepted statistically according to its society.

Most of the sample came from females (64.2\%), the age group of 21: 30 years $(50.5 \%)$ and 31: 50 years $(46.8 \%)$, which is the category that interacts with the markets, because it is the most expected group that is committed to providing the requirements of families. The marital status ratios of the married category (presumably the most in need of goods) were balanced with the proportions of the single and not dependent (the most category with plenty of time). The questionnaire sample also focused on the most cultural category the group affected by technological. So, the group of graduate $(55.0 \%)$ and postgraduate $(43.1 \%)$ degree holders dominated the sample. As seemed in (Figure 9) \& (Figure 10) \& (Table 2).

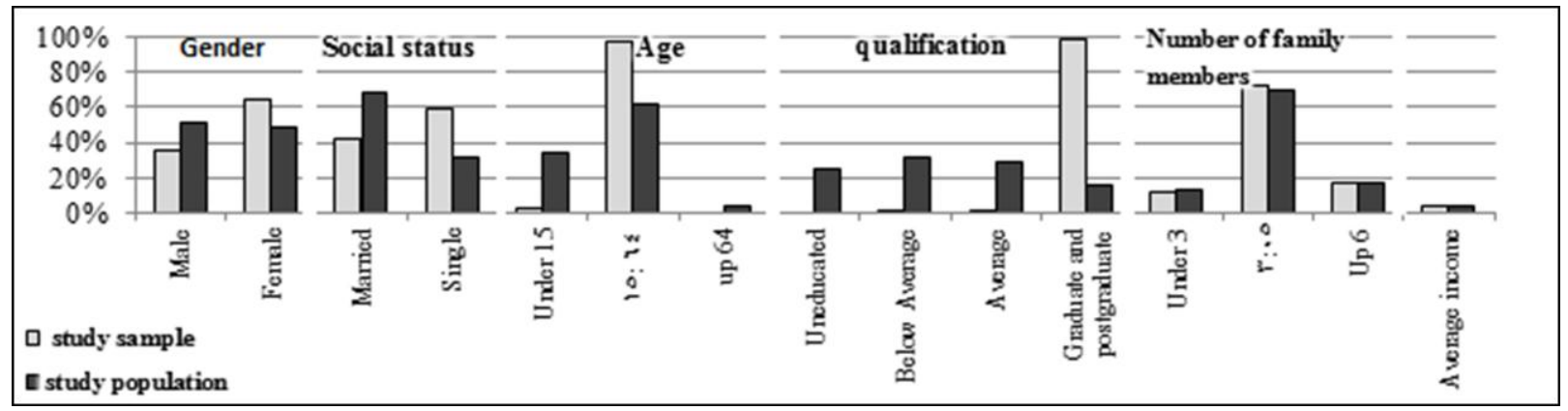

Figure 9: Representing the percentages of the study sample groups and the study population according to their characteristics [7].

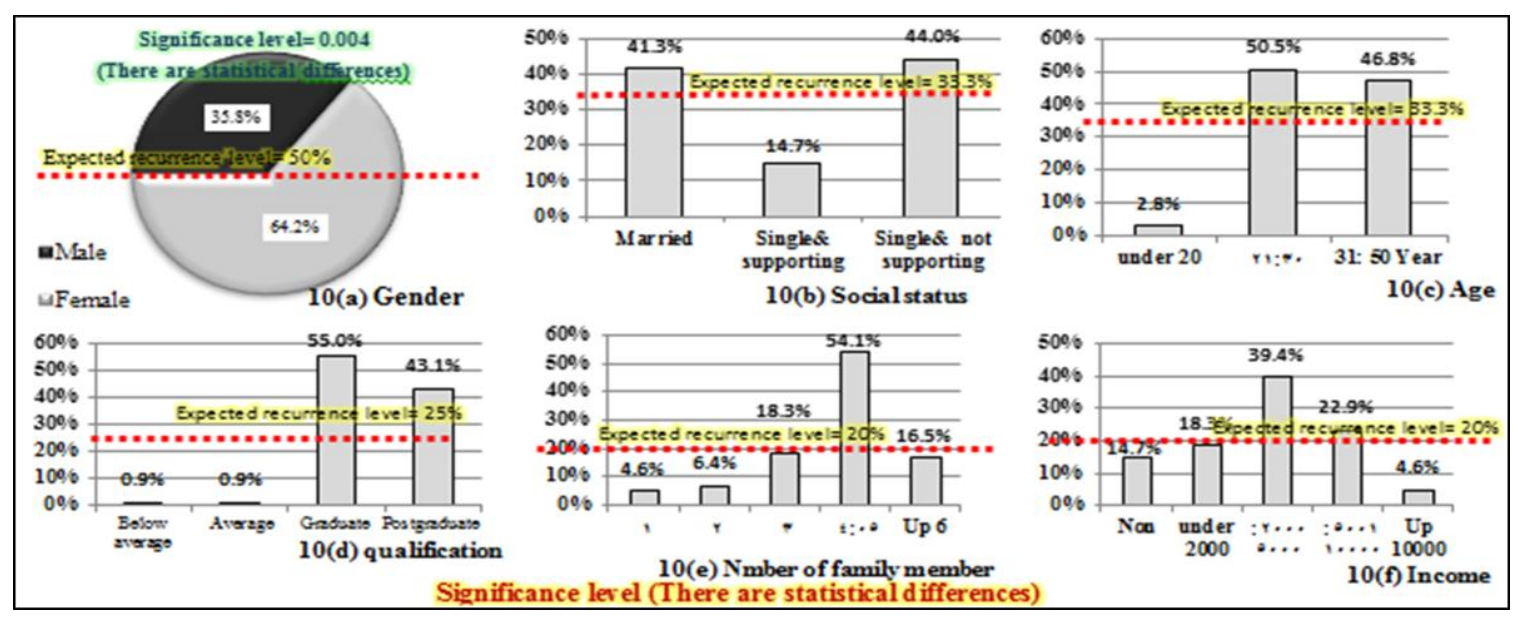

Figure 10: A representation of the percentages of the study sample categories according to personal characteristics, signed by the expected frequency [7]. 


\subsubsection{Correlation coefficient measure:}

The results of the linear correlation study between the proportions of the sample data and the study population showed that there is a direct correlation between the percentages of the questionnaire sample and the proportions of the study population.

The value of the statistical significance level is less than the 5\%. So, we accept the alternative hypothesis. The correlation value with the Spearman method is 0.537 , and the correlation value with the Kendall method is 0.430 . It was found that the study sample was statistically similar to its community. As seemed in (Table 3).

\subsubsection{Measurement of differences between samples}

The difference test was applied between the percentages of personal data for the study sample and the 2017 census rates for the Arab Republic of Egypt. The results of the population group and study sample ratios were once entered as independent samples to apply the Independent Samples Mann-Whitney U Test.

There was no significant difference between the values of the study population and sample at the significance level 0.05 , as the value of the significance level Equals 0.317 (above 0.05). The results of the percentages of the population groups and the study sample were entered again as interrelated samples.

The researcher applied the related Samples Wilcoxon Signed Ranks Test. The test results showed that there were no significant differences at the significance level 0.05 , as the significance level was 0.492. As seemed in (Table 4).

After the research applied correlation and differences between the study sample and their original community. It becomes clear that the results of the questionnaire circulated to the study population, because of their convergence in features and characteristics are statistically acceptable and logically acceptable according to the results of previous studies.

Table 2: The proportions of the study sample categories and the study population according to their personal characteristics and the type of correlation between their values [7].

\begin{tabular}{|c|c|c|c|c|c|c|c|c|c|c|c|c|c|c|c|}
\hline & \multicolumn{2}{|c|}{ Gender } & \multicolumn{2}{|c|}{ Social status } & \multicolumn{3}{|c|}{ Age } & \multicolumn{4}{|c|}{ Qualification } & \multicolumn{3}{|c|}{$\begin{array}{c}\text { Number of family } \\
\text { members }\end{array}$} & \multirow[b]{2}{*}{ 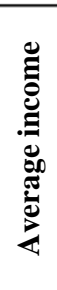 } \\
\hline & $\frac{\stackrel{N}{\pi}}{\sum}$ & 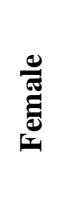 & 胥 & $\begin{array}{l}\frac{0}{00} \\
\stackrel{\Xi}{*}\end{array}$ & م & $\begin{array}{l}\vec{b} \\
\ddot{n}\end{array}$ & $\begin{array}{l}\vec{b} \\
\underline{b}\end{array}$ & 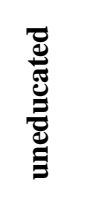 & 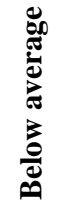 & Uू & 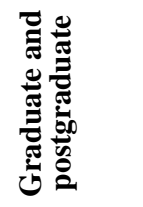 & $\stackrel{m}{\stackrel{0}{0}}$ & $\ddot{m}$ & $\begin{array}{l}b \\
b\end{array}$ & \\
\hline *study population & 51.6 & 48.4 & 68 & 32 & 34.2 & 61.9 & 3.9 & 25.8 & 32.3 & 29.1 & 15.5 & 13 & 69.7 & 17.3 & 3.7 \\
\hline study sample & 35.8 & 64.2 & 41.3 & 58.7 & 2.8 & 97.3 & 0 & 0 & 0.9 & 0.9 & 98.1 & 11 & 72.4 & 16.5 & 3.9 \\
\hline Correlation Coefficient & \multicolumn{2}{|c|}{${ }^{* *}-1.00-$} & \multicolumn{2}{|c|}{${ }^{* *}-1.00-$} & \multicolumn{3}{|c|}{${ }^{* *} 1.00$} & \multicolumn{4}{|c|}{ Significance level is above 0.05} & \multicolumn{3}{|c|}{${ }^{* *} 1.00$} & - \\
\hline Correlation type & \multicolumn{2}{|c|}{$\begin{array}{l}\text { Completely } \\
\text { inverse }\end{array}$} & \multicolumn{2}{|c|}{$\begin{array}{l}\text { Completely } \\
\text { inverse }\end{array}$} & \multicolumn{3}{|c|}{ Completely direct } & \multicolumn{4}{|c|}{$\begin{array}{l}\text { Not statistically significant } \\
\text { [[relationship can't be generalized }\end{array}$} & \multicolumn{3}{|c|}{ Completely direct } & - \\
\hline
\end{tabular}

.The Arab Republic of Egypt Census, 2017*

Table 3: Correlation between the proportions of the population and the study sample [7].

\begin{tabular}{|c|c|c|c|c|c|c|}
\hline Relationship elements & $\begin{array}{c}\begin{array}{c}\text { Correlation } \\
\text { method }\end{array} \\
\end{array}$ & $\begin{array}{l}\text { Correlation } \\
\text { Coefficient }\end{array}$ & $\begin{array}{l}\text { Sig. [2- } \\
\text { tailed] }\end{array}$ & $\begin{array}{c}\text { Correlation } \\
\text { type }\end{array}$ & $\begin{array}{c}\text { Correlation } \\
\text { strength } \\
\end{array}$ & The result \\
\hline \multirow{2}{*}{$\begin{array}{c}\text { Sample questionnaire and study } \\
\text { population }\end{array}$} & Spearman's rho & $.537^{*}$ & .026 & \multirow[b]{2}{*}{ direct } & strong & \multirow{2}{*}{$\begin{array}{l}\text { The study sample was statistically } \\
\text { similar to the study population }\end{array}$} \\
\hline & Kendall's tau_b & $.430^{*}$ & .017 & & Average & \\
\hline
\end{tabular}

*. Correlation is significant at the 0.05 level [2-tailed].

Table 4: Results of testing the differences between the questionnaire sample and the study population[7].

\begin{tabular}{|c|c|c|c|c|c|c|c|c|}
\hline \multicolumn{2}{|c|}{ Independent Samples Mann-Whitney U } & \multicolumn{7}{|c|}{ Related Samples Wilcoxon Signed Ranks Test } \\
\hline $\begin{array}{c}\text { Total N } \\
\text { Sample volume }\end{array}$ & $\begin{array}{c}2 \text { [Sample } \\
\text { questionnaire and } \\
\text { study population] }\end{array}$ & & & $\mathrm{N}$ & $\begin{array}{l}\text { Mean } \\
\text { Rank }\end{array}$ & $\begin{array}{c}\text { Sum } \\
\text { of } \\
\text { Ranks }\end{array}$ & Test Statistics & \\
\hline Mann-Whitney U & .000 & Sample & Negative Ranks & $10^{\mathrm{a}}$ & 9.10 & 91.00 & Total N & 17 \\
\hline $\begin{array}{c}\text { Wilcoxon W } \\
\text { Z }\end{array}$ & $\begin{array}{r}1.000 \\
-1.000-\end{array}$ & $\begin{array}{l}\text { questionnaire - } \\
\text { Census study }\end{array}$ & $\begin{array}{c}\text { Positive Ranks } \\
\text { Ties }\end{array}$ & $\begin{array}{l}7^{\mathrm{b}} \\
0^{\mathrm{c}}\end{array}$ & 8.86 & 62.00 & $\begin{array}{l}\text { Test Statistic } \\
\text { Standard Error }\end{array}$ & $\begin{array}{l}62.00 \\
21.11\end{array}$ \\
\hline $\begin{array}{l}\text { Asymp. Sig. [2- } \\
\text { tailed] }\end{array}$ & .317 & population & Total & 17 & & & Standardized Test Statistic & $.687-$ \\
\hline $\begin{array}{c}\text { Exact Sig. [2*[1- } \\
\text { tailed Sig.]] }\end{array}$ & $1.000^{\mathrm{b}}$ & a] questionn & $\begin{array}{l}\text { e }<\text { Egypt b] } \mathrm{c} \\
\text { c] questionnaire }=\end{array}$ & stion & ire $>\mathrm{I}$ & & Asymp. Sig. [2-tailed] & .492 \\
\hline
\end{tabular}




\subsection{Results of the activities axis associated with shopping in the Egyptian markets}

Individual options have shown that there is an imbalance in the social role that Egyptian markets are supposed to play, as most of the sample did not favor shopping for social media (11\% of the total sample). The Egyptian community clearly missed the neighborhood relationship, where a low shopping rate was observed with the neighbors $(0.9 \%$ of the total sample is shopping with the neighbors), and the sample choices ranged in that the frequency of non-commercial elements in the market at an average rate $(42.2 \%$ of the total sample) Or less than the average (38.5\% of the total sample).

It shows the beginning of the activity acceptance and development of markets to lead its social role in the convergence of the sample choices in going to the market for entertainment and walking, preferring shopping with family ( $60.6 \%$ of the total sample), and attracting most of the sample to frequent non-commercial elements at an average rate $(42.2 \%)$. The sample attributed the reason for the frequency rate on nonstores to amusement and entertainment (32.3\%), in addition to the preference for frequency on more than one store when purchasing a commodity, and the absence of strong differences between choosing or not choosing shopping for entertainment, walking and the pleasure of shopping, and preferring shopping with friends (49,5\%). As seemed in (Figure 11).

\subsubsection{Correlation coefficient with the associated activity axis}

The research studied the results of the Spearman's coefficient of rank correlation and Kendall Correlation Coefficient between the study sample personal data and the accompanying activity axis questions. It turns out that the groups that are ready for social interaction within the markets are the younger age group, those with the lowest qualifications and those with low incomes. As seemed in (Table 5).

\subsubsection{Differences between samples in the accompanying activity axis}

The Chi-square test was used with the Cross tabs command to study the differences between the study sample directions in the accompanying activity axis classified according to the personal data and the reason for going to the markets. A test detects the presence or absence of a relationship between two variables at the significance level 0.05 . If there is a relationship between the two variables, it can be said that the two variables are related.

It shows the willingness of some groups for social interaction within the markets, and they are the single\& not supporting groups, the married group, the less than 20 years group, the 21 to 30 years group, the owners of the average qualification, less than the average followed by the university qualification, the monthly income category more than 10,000 , the group that has no income Private and the group with an income less than 2000 pounds. As seemed in (Table 6) \& (Figure 12).

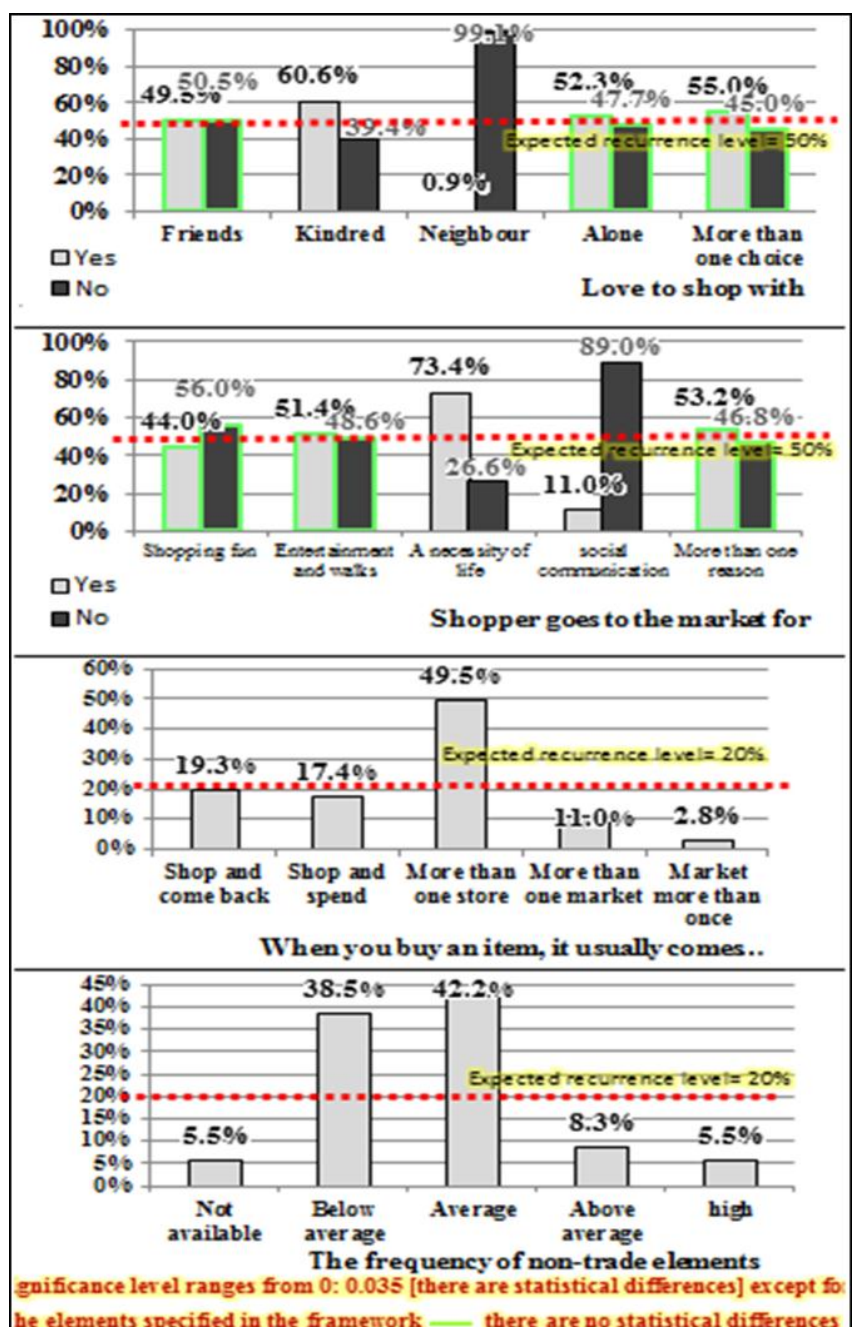

Figure 11: A representation of the percentages of the total study sample at the axis of the accompanying activity, signed by the expected frequency [7].

Table 5: Correlated elements according to the correlation coefficient with the associated activity axis [7].

\begin{tabular}{|c|c|c|c|c|c|c|}
\hline & \multicolumn{3}{|c|}{ Correlation components } & \multicolumn{2}{|c|}{ Correlation coefficient } & \multirow[b]{2}{*}{$\begin{array}{c}\text { Correlation } \\
\text { type }\end{array}$} \\
\hline & $\begin{array}{c}\text { The first } \\
\text { component }\end{array}$ & & $\begin{array}{l}\text { e second } \\
\text { nponent }\end{array}$ & $\begin{array}{c}\text { Spearman's } \\
\text { rho }\end{array}$ & $\begin{array}{c}\text { Kendall's } \\
\text { tau_b }\end{array}$ & \\
\hline \multirow{3}{*}{ 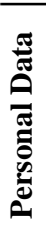 } & Age & 吾 & $\begin{array}{l}\text { friends } \\
\text { alone }\end{array}$ & $\begin{array}{l}-.196^{*} \\
.234^{*}\end{array}$ & $\begin{array}{l}-.193^{*} \\
.231^{*}\end{array}$ & $\begin{array}{l}\text { inverse } \\
\text { direct }\end{array}$ \\
\hline & aualification & 를 & friends & $-.247-^{* *}$ & $-.245-^{*}$ & inverse \\
\hline & Income level & $\stackrel{\substack{0 \\
0}}{0}$ & $\begin{array}{l}\text { alone } \\
\text { friends } \\
\text { alone }\end{array}$ & $\begin{array}{l}.325^{* *} \\
-.193^{*} \\
.200^{*}\end{array}$ & $\begin{array}{c}.322^{* *} \\
-.176-^{*} \\
.182^{*}\end{array}$ & $\begin{array}{l}\text { direct } \\
\text { inverse } \\
\text { direct }\end{array}$ \\
\hline
\end{tabular}

\subsection{Results of the Shopper Satisfaction axis about Egyptian markets}

The sample's choices in the frequency of visits to the market were approximated between one to two times a week and usually more than two weeks. That choice was justified due to the pattern of need and the average time available, which indicates the shopper's loss of attractions and pleasure during his/ her trip in the Egyptian markets. This is confirmed by the bias of a number of the sample to spend only two to three hours on the shopping trip. 
Table 6: The correlated elements of the activity axis associated with the personal data according to the Chi-square independence test [7]

\begin{tabular}{|c|c|c|c|c|c|c|c|}
\hline \multicolumn{3}{|c|}{ Non-independent components } & \multirow{2}{*}{ df } & \multirow{2}{*}{$\underset{X^{2}}{\text { Value }}$} & \multirow{2}{*}{$\begin{array}{l}\text { Sig. }(2- \\
\text { sided })\end{array}$} & \multicolumn{2}{|l|}{ Study mode } \\
\hline First & & Second component & & & & Describe & Effect \\
\hline \multirow{7}{*}{ 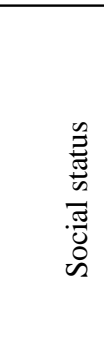 } & \multirow{7}{*}{$\begin{array}{l}\text { D. } \\
3 \\
0 \\
0 \\
\frac{0}{0} \\
0 \\
0 \\
0 \\
0 \\
0\end{array}$} & \multirow{7}{*}{ alone } & 2 & 5.791 & 0.055 & $\begin{array}{c}\text { Single\& not supporting group was attracted to shopping more with } \\
\text { friends }\end{array}$ & Note \\
\hline & & & & \multirow{6}{*}{10.591} & & Married and single\& not supporting group did not prefer shopping & \\
\hline & & & & & & more with friends & \\
\hline & & & & & & & \\
\hline & & & & & & $\begin{array}{l}\text { There are not strong differences between the choices of a single\& } \\
\text { not supporting group for shopping with kindred }\end{array}$ & \\
\hline & & & & & & $\begin{array}{c}\text { There are not strong differences between the choices of a single\& } \\
\text { supporting group for shopping with kindred }\end{array}$ & - \\
\hline & & & & & & A single\& supporting group did not prefer more than one choice & - \\
\hline
\end{tabular}

Shopper goes to the market $\quad 2 \quad 8.591 \quad 0.011$

for Life necessity

气ี๊

Love to shop with alone $\quad 2 \quad 6.001 \quad 0.050$

$\frac{1}{2}$

Shopper fun shopping $\quad 4 \quad 11.426 \quad 0.022$ goes to the

market for

$3 \quad 11.876 \quad 0.008$

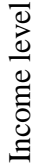

$\begin{array}{cccc}\begin{array}{c}\text { Social } \\ \text { communication }\end{array} & 4 & 9.640 & 0.047 \\ \begin{array}{c}\text { Shopper goes to the } \\ \text { market with friends }\end{array} & 4 & 9,612 & 0.047\end{array}$

Above 21 years old group was attracted to shopping for a life necessity

Under 20 years old group was not attracted to shopping for a necessity of life

31: 50 years old group was attracted to shopping alone

21:30 years old group was not attracted to shopping alone

There are not differences between the choices of under 20 years group for shopping alone

Postgraduate is attracted to shopping alone

Graduate, Average, and under average groups are not attracted to shopping on their own

Non income and up 10,000 groups go to the market for fun shopping

Under 2000 to 10,000 income groups did not go to the market for the pleasure of shopping

All groups weren't attracted to going to the market for social communication

A class with no income and less than 2000 income groups were attracted to shopping with friends

2001: 5000 group was not attracted to shopping with friends

There are not differences between the choices of 5001: more than 10,000 for shopping with friends
Confi-rmation

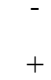

Note

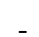

$+$

$+$

$-$

$+$

Note $+\quad$ A positive component of the study needs support

A negative component of the study needs to be addressed
Categories are ready for social interaction within the markets A negative element confirms the weak social role of markets

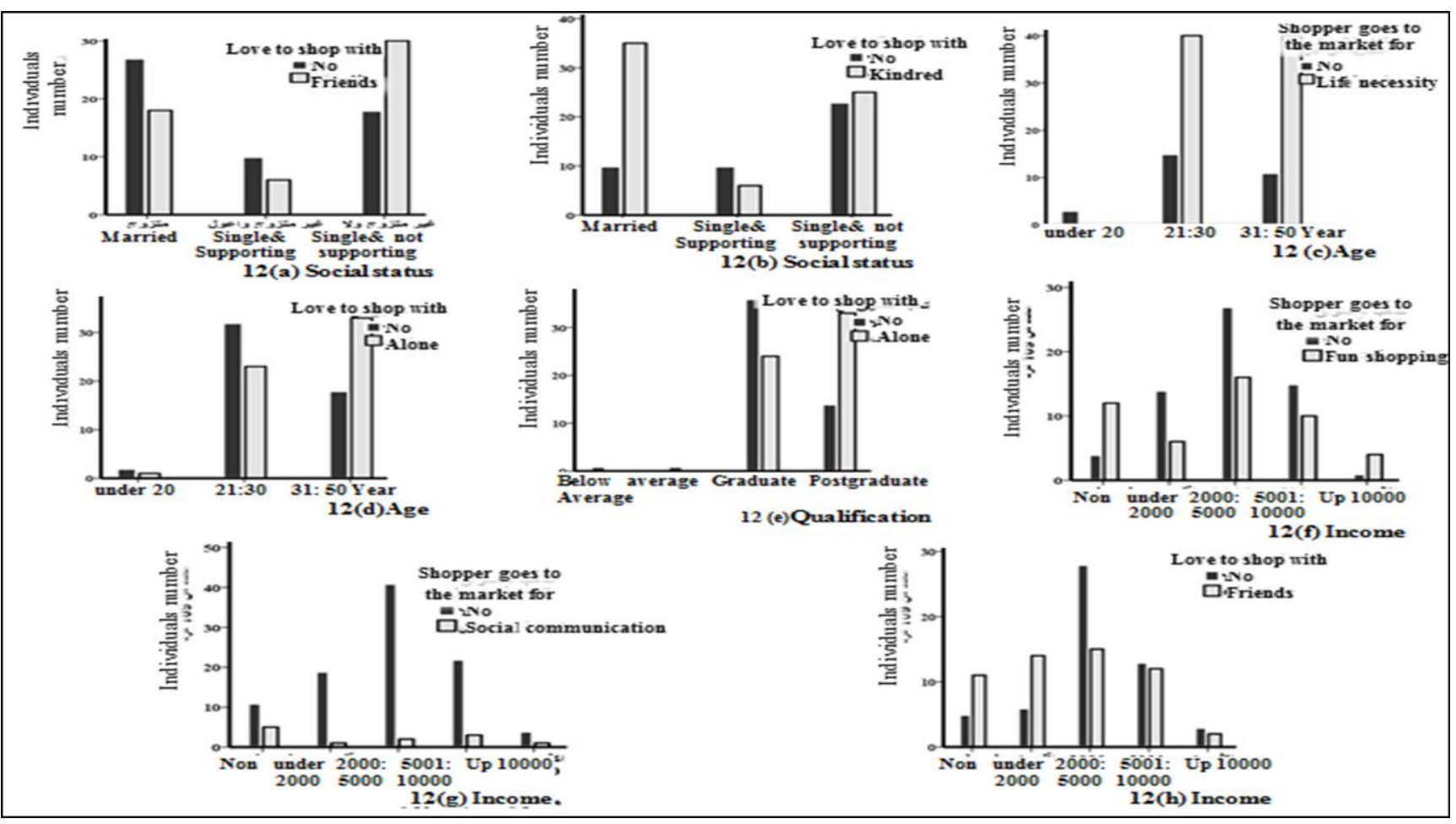

Figure 12: A representation of the elements related to the activity axis associated with the personal data according to the independence test [7]. 
The shopping style of the sample members is considered to be almost constant, as the attraction of the sample tended to hesitate on the same market. This means that previous experiences strongly influence the behavior of the shopper, and therefore the shopper's first experience of any change in the markets will have a significant impact. The shopper attributed the reason for its repeated purchase from the same market to commodities $(39,5 \%)$ and then the location of the housing $(27$, $5 \%)$. It is noticeable that the shopper is less attracted to the entertainment and supplemental elements in the market $(6,4 \%)$, which is a negative indication of the current market situation.

The researcher observed the satisfaction of the study sample for the situation of the Egyptian urban markets, so the study sample felt comfortable and affliction within the markets at an average rate (45\% of the study sample) then an above average rate (21.1\% of the study sample) and then a high rate (15.6\% From the study sample). As seemed in (Figure 13).

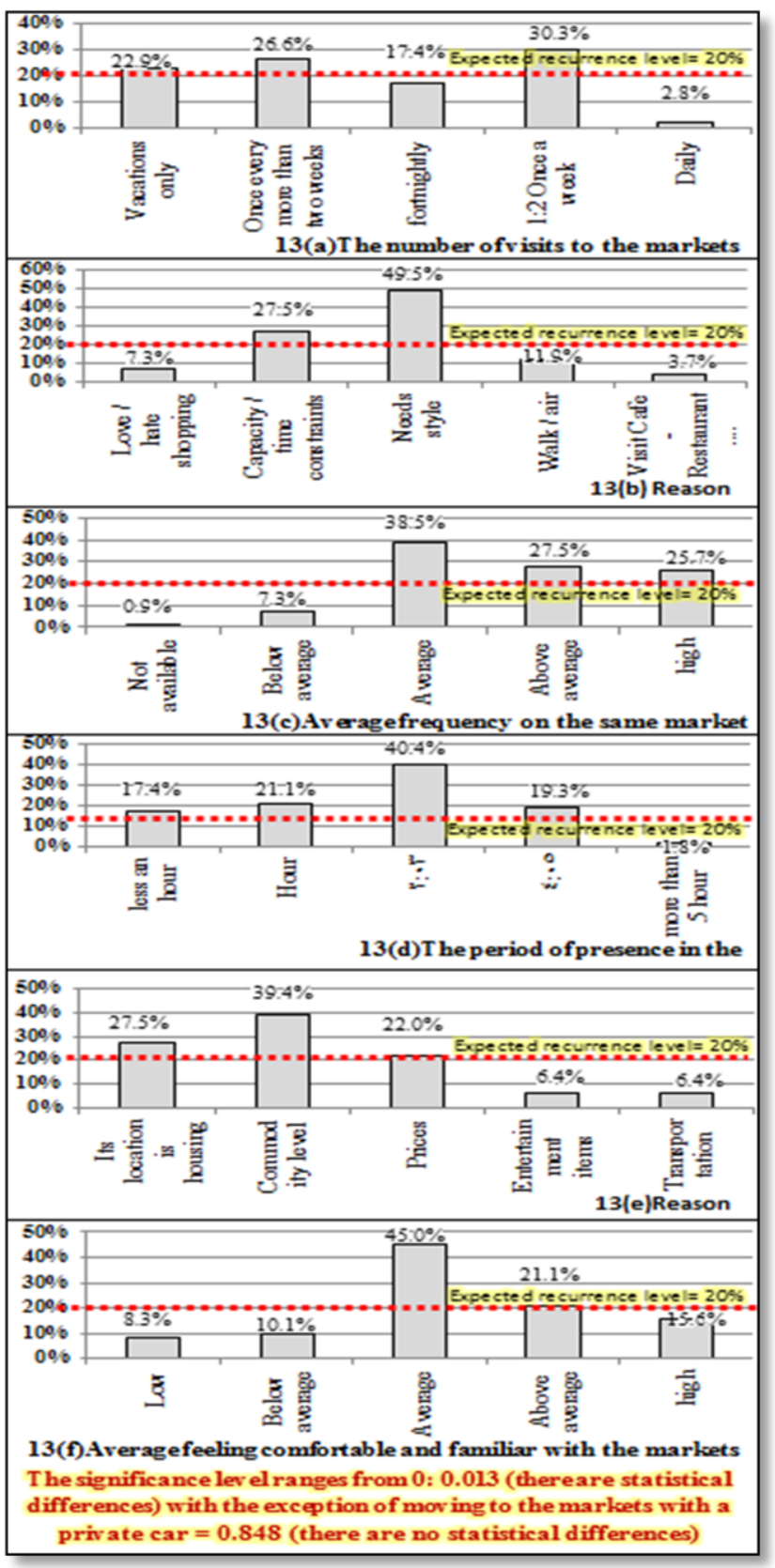

Figure 13: A representation of the percentages of the total study sample, at the axis of satisfaction with the commercial markets[7].

\subsubsection{The correlation with the market satisfaction:}

The research studied the results of the Spearman's coefficient of rank correlation and Kendall Correlation Coefficient between the study sample personal data the market satisfaction axis questions, and between the axis questions and some of them.

It turns out that the older age groups frequently visit the market, but they spend short time periods and vice versa for the younger age groups (due to the time and need). People with less income and the lower qualification group spend longer periods of time than others within the market, and lower income groups are frequented by the market during the night hours (in search of thermal comfort). The frequency increases on the same market from families with many members. The increase in the rate of feeling comfortable was associated with the increase in the number of visits to the market and the increase in the period of presence in the market. As seemed in (Table 7).

\subsubsection{Differences between samples in the satisfaction axis from markets}

The Chi - square test was used with the Cross tabs command to study the differences between the directions of the study sample in the satisfaction of markets, classified according to the personal data, and the reason for going to the markets. A test detects the presence or absence of a relationship between two variables at the significance level 0.05. As seemed in (Table 8) \& (Table 9) \& (Figure 14) \& (Figure 15).

\section{Conclusions}

The field study showed that associative activities in Egypt have kept markets out of the right path to social marketing.

The contemporary Egyptian markets need to create societal value in the proper way consistent with the social orientation of marketing, this is achieved by the contribution of markets in the pursuit of developing members of society and bringing about changes in the behavior of members of society.

The paper found out those associative activities is a way to add value to shopping other than merely buying goods. The associative activities may have different interfaces, but social interaction is the most proffered activity to have in the markets due to the nature of people in Egypt. Socialization may be within shoppers and their accompanying as friends or family members, or shoppers and Sellers as in popular markets.

The research will lay out the study conclusions [indicators supporting the social orientation of marketing in the Egyptian urban markets], based on the relationships observed through the questionnaire form, observations of field visits to Egyptian markets, and a quote from the directives of theories of social change and theories of behavior change. The content of these theories is scientific methods that can be used to make deliberate changes in social reality in order to achieve the goals of social marketing. 
Table 7: Correlated elements according to the correlation coefficient with the market satisfaction index [7].

\begin{tabular}{|c|c|c|c|c|c|}
\hline \multicolumn{3}{|c|}{ Correlation components } & \multicolumn{2}{|c|}{ Correlation coefficient } & \multirow{2}{*}{$\begin{array}{c}\text { Correlation } \\
\text { type }\end{array}$} \\
\hline & The first component & The second component & Spearman's rho & Kendall's tau_b & \\
\hline \multirow{9}{*}{ 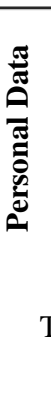 } & 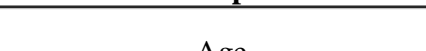 & The number of visits to the markets & $.206^{*}$ & $.187^{*}$ & direct \\
\hline & Age & The period of presence in the market & $-.193-*$ & $-.175-^{*}$ & \\
\hline & gualification & & $-.215-^{*}$ & $-.196-{ }^{*}$ & inverse \\
\hline & qualification & The best time to shop & $-.254^{* *}$ & $-.2311^{* *}$ & \\
\hline & number of family members & Average frequency on the same market & $.210^{*}$ & $.185^{*}$ & direct \\
\hline & Income level & The neriod of nresence in the market & $-.252^{* *}$ & $-.211-^{* *}$ & inverse \\
\hline & & 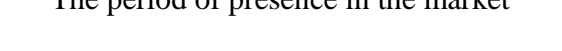 & $-.233-*$ & $-.202-^{*}$ & minerse a gat a \\
\hline & e number of visits to the markets & The shopper feels comfortable and familiar & $.258^{* *}$ & $.215^{* *}$ & direct \\
\hline & You are on the market & 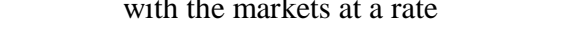 & $.190^{*}$ & $.160^{*}$ & \\
\hline
\end{tabular}

Table 8: The correlated elements of the satisfaction axis of the markets with personal data according to the Chi-square independence test [7].

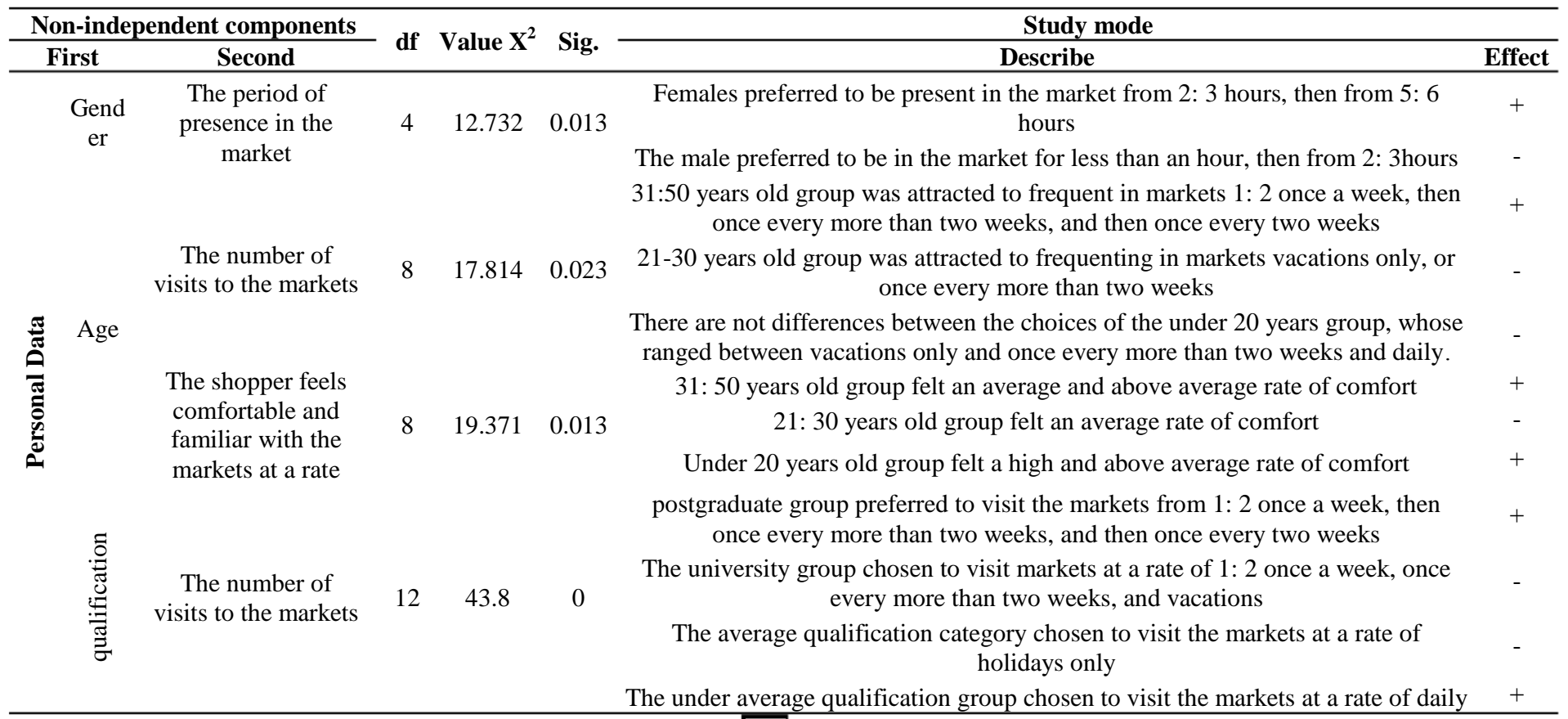

A positive component of the study needs support

A negative component of the study needs to be addressed
Categories are ready for social interaction within the markets

A negative element confirms the weak social role of markets

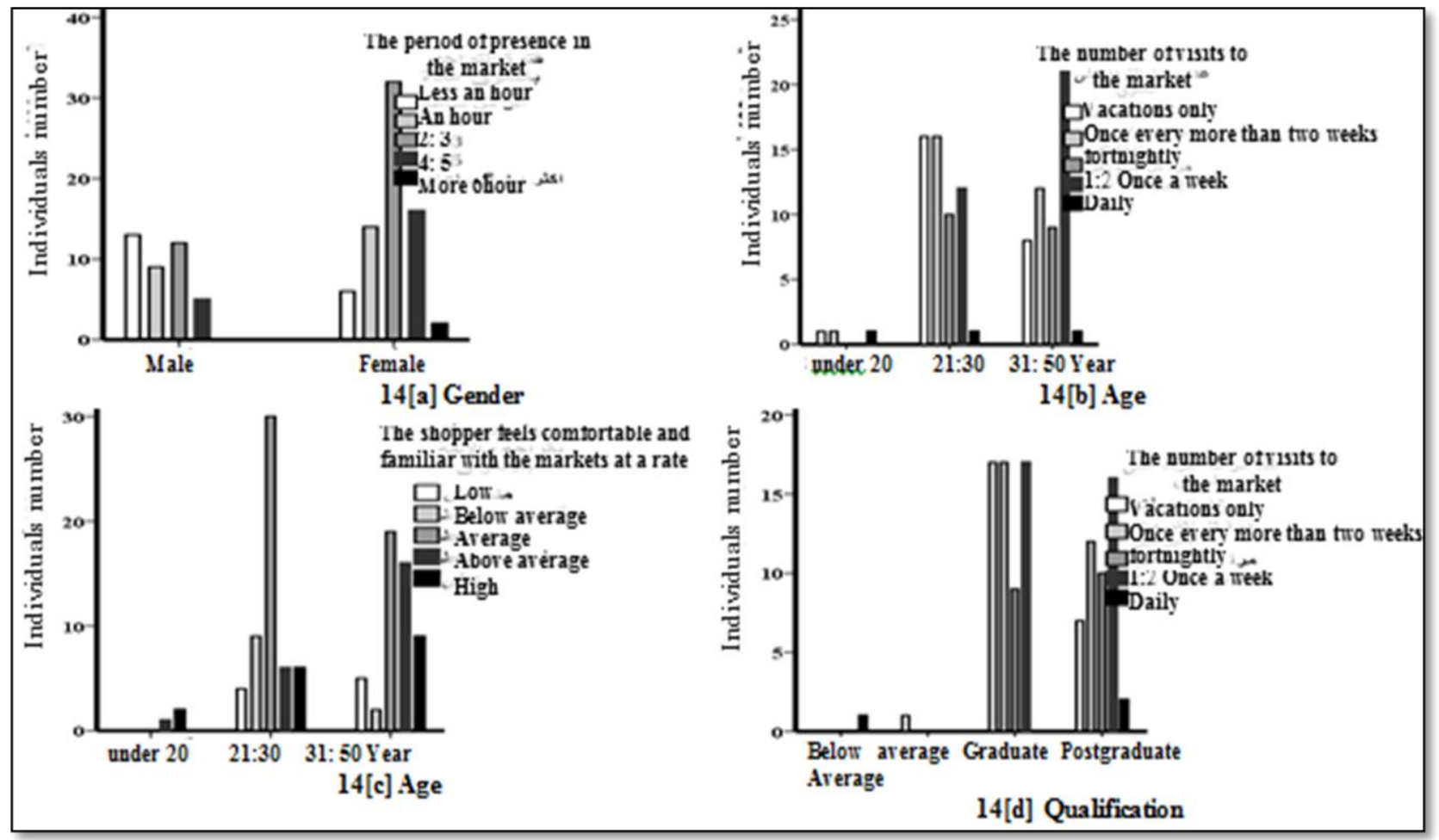

Figure 14: A representation of the elements correlated to the market satisfaction axis with personal data, according to the independence test [7] 
Table 9: The correlated elements of the market satisfaction axis with the reason for going to the markets according to the test of the independence of Chi-square with determining the direction of its association [7].

\begin{tabular}{|c|c|c|c|c|c|}
\hline \multicolumn{3}{|c|}{ Non-independent components } & \multirow{2}{*}{\multicolumn{2}{|c|}{ df Value $X^{2}$}} & \multirow[t]{2}{*}{ Sig. } \\
\hline & st component & Second component & & & \\
\hline & $\begin{array}{c}\text { fun } \\
\text { shopping }\end{array}$ & $\begin{array}{c}\text { The period of presence in } \\
\text { the market }\end{array}$ & 4 & 9.881 & 0.042 \\
\hline & & $\begin{array}{l}\text { The shopper feels } \\
\text { comfortable and familiar } \\
\text { with the markets at a rate }\end{array}$ & 4 & 16.850 & 0.002 \\
\hline 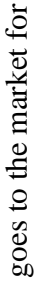 & $\begin{array}{l}\text { entertainment } \\
\text { and strolling }\end{array}$ & $\begin{array}{l}\text { Reason (The number of } \\
\text { visits to the markets) }\end{array}$ & 4 & 14.344 & 0.006 \\
\hline $\begin{array}{l}\overline{\bar{\nu}} \\
\frac{2}{2} \\
\overline{\frac{1}{2}}\end{array}$ & Life necessity & & 4 & 16.432 & 0.002 \\
\hline
\end{tabular}

Social communicatio

$$
\mathrm{n}
$$

\section{The period of presence in $\quad 4 \quad 10.350 \quad 0.035$ the market}

Non-independent components

Describe
Group goes to the market for the fun of shopping. This group
is in the market for $2: 3$ hour
is in the market for 2: 3 hour

Group doesn't go to the market for the fun of shopping. This group is in the market from 2: 3 hours, then less than an hour and an hour

Group goes to the market for the fun of shopping. This group felt an average, then above average and high rate of comfort Group doesn't go to the market for the fun of shopping. This group felt an average rate of comfort

Group goes to the market for entertainment and strolling. This group chosen the reason for the frequency of the markets due to the need style, then the capacity/ the limited time for shopping.

Group doesn't go to the market for entertainment and strolling. This group chosen the reason for the frequency of the markets due to the need style

Group goes to the market for life necessity. This group chosen the reason for the frequency of the markets due to the need style.

Group doesn't go to the market for life necessity. This group chosen the reason for the frequency of the markets due to walk/ air, needs style, and the capacity/ the limited time for shopping

Group goes to the market for the social communication. This group is in the market from 4: 5 hours, then from 2: 3 hours Group doesn't go to the market for the social communication. This group is in the market from 2: 3 hours

Categories are ready for social interaction within the markets A negative element confirms the weak social role of markets

$+\quad$ A positive component of the study needs support

- A negative component of the study needs to be addressed

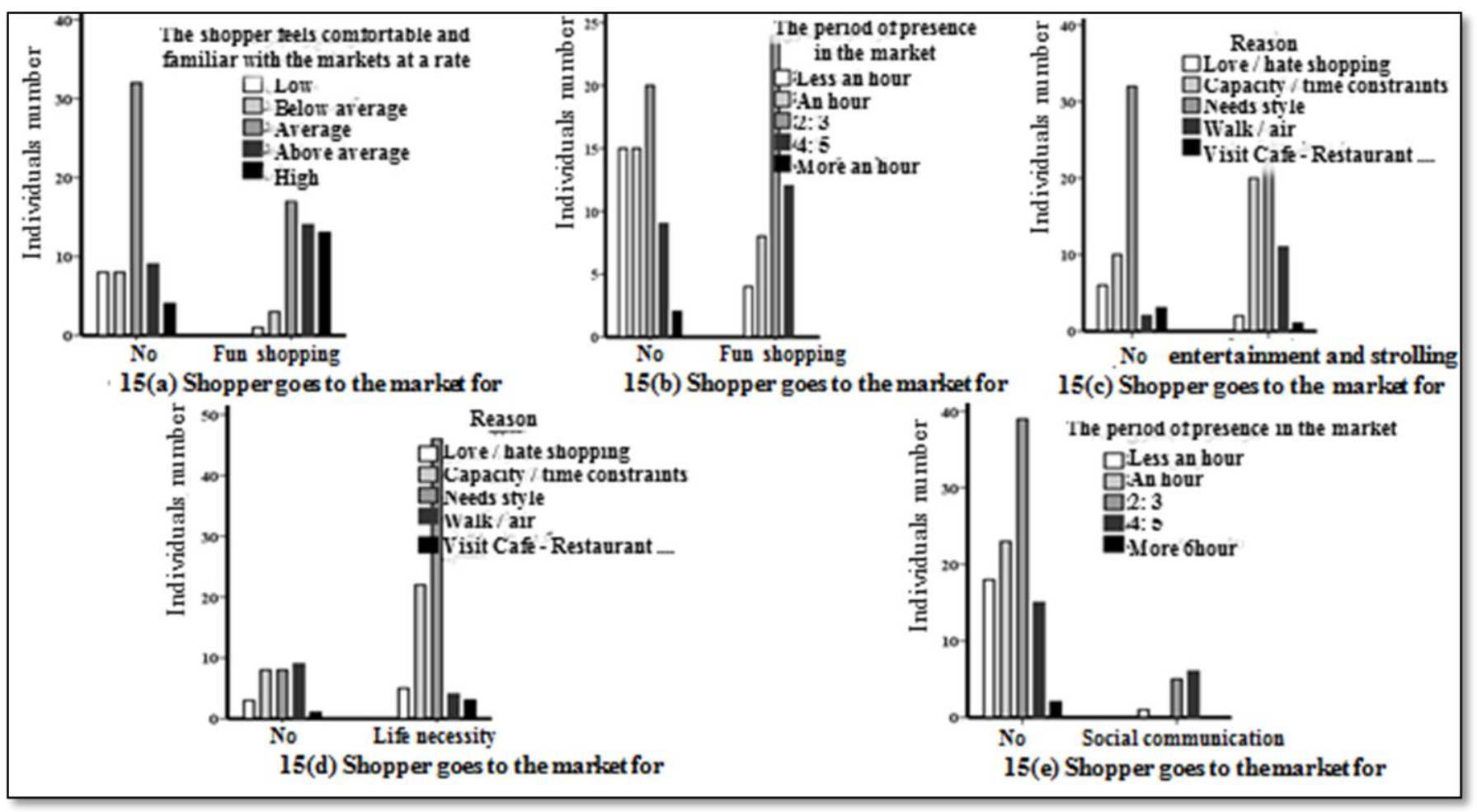

Figure 15: A representation of the elements related to the satisfaction hub of the markets with the reason for going to the markets according to the independence test [7]. 


\subsection{Conclusion of the points supporting the social orientation of marketing in the Egyptian urban markets}

We need to learn ${ }^{[a]}$ the shopper away from the consumer's behavior of the marketer and urge the shopper to produce (a kind of market contribution to solving the problems of their community). A stimulus must be created for the shopper, and the appropriate atmosphere must be created to acquire the desired behavior, in order for the shopper to reach full maturity. This learning falls under the group learning pattern, targeting the largest possible number of shoppers.

This could be by adding a new item in the market that is attractive for shopping in tangible markets. The item produces a shopping activity with an educational development dimension. The activity contributes to directing community members in accordance with the policies and needs of their country (workers - production). The activity creates a distinct personality for each market that suits the situation in the urban area, and the shopper feels familiarity and the pleasure of shopping. The accompanying activity contributes to the association of the members of society with their homeland, in addition to developing the personal skills of the community members, their social communication in a tangible reality, and learning them activities that must be compatible with the needs of the labor market. Human wealth is considered one of our most important natural ingredients.

The research proposes relying on Modeling \& Imitation method $^{[b]}$ because there is a real interaction between the shopper and the team based on shopper learning.

${ }^{\text {[a] }}$ Learning: The change in performance is caused by the influence of the surrounding environment or what an individual does and observes. Arthur Gates defined learning as the process of gaining ways that make a person satiate his/ her motivations, achieve his/ her goals and be able to solve his/ her problems.

John Lock defined the learning as a process of training the mind on specific skills (skill of thinking, remembering or imagining ....) to benefit from it in a field that helps him/ her to use these faculties in other fields.

[b] Modeling: The individual observes a model that performs the desired behavior, so the individual is affected by the model and learns from it by simulation, so he acquires his behavior or part of his behavior [21].

Points were suggested to support the social role of the Egyptian market:-

1. The designer creates general, flexible, multi-use spaces in which the shopper engages in various activities (the activity associated with shopping] with a development dimension. The activity should strengthen the shopper's skills [mental manual - visual ...). It is preferable to direct the shopper to participate in the activity, as the activity attracts him/ her from consumption. The accompanying activity guides the shopper for business needs in the market area. Activity vacuums must be placed on important visual axes within the urban markets (linked to the aggregate market spaces and important traffic corridors). The shopper sees the void, and feels the activity practiced in it, with or without intention (as a kind of invitation to participate in the activity inside the market).

2. It is proposed to exploit the atrium vacuum, which is found in the aggregate voids of the mall. The shopper will engage in proposed development activities. Then, the visitors are familiar with the mall's activity in the market, and the activity is in direct contact with the upper floors of the mall building. As seemed in (Figure 16).

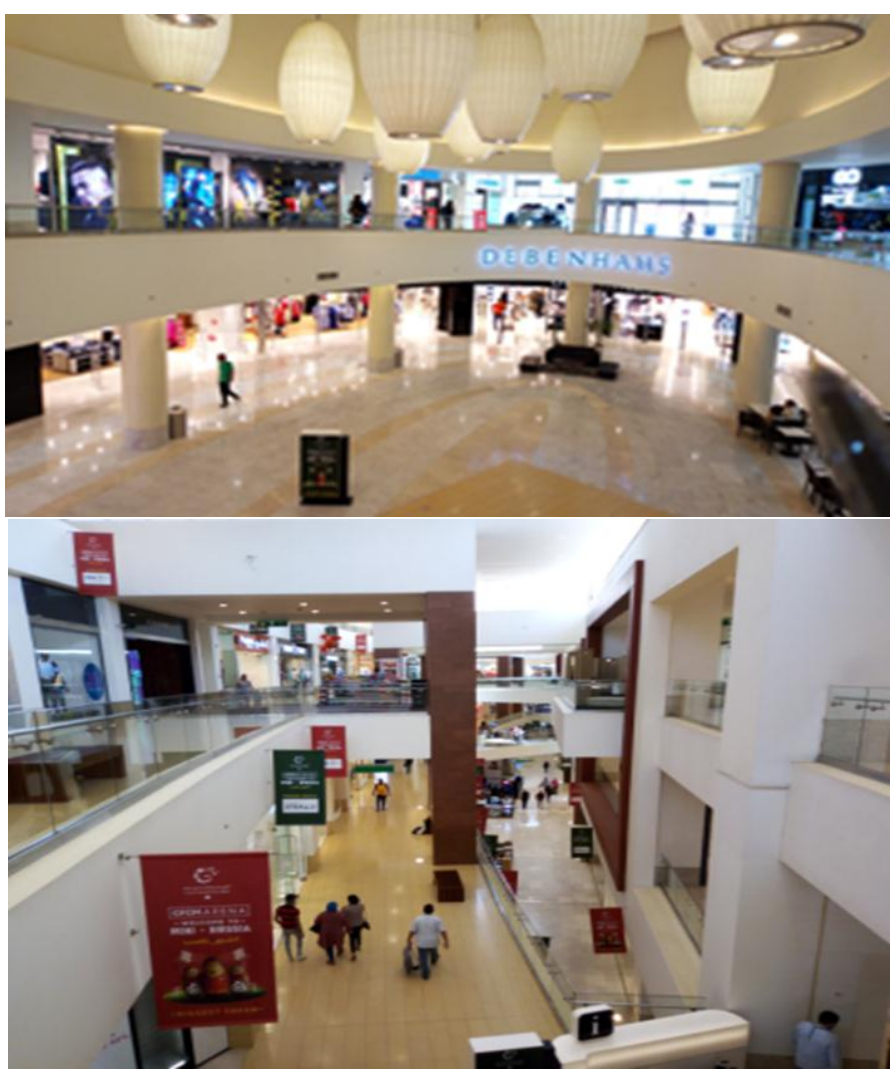

Figure 16: Atrium is a model of spaces that can be used for activities associated with the Mall (Cairo Festival Mall in New Cairo in Egypt) [7].

3. The static voids generated alongside the corridor of movement in the linear markets. It can be exploited in the accompanying development activity. As seemed in (Figure 17)

4. The accompanying added activity must be commensurate with the situation of the urban area of the market, the patterns of goods produced and crafts adjacent to the market area. The shopper will know and relate to the market through the accompanying added activity. The shopper will acquire information and skill that he can use in his personal life (produces simple handicrafts that he benefits personally) or his career (Individuals are directed to work in a specific field that his community needs - Individuals are opened the vision for him to create a small or large project that produces goods that his community needs or meets the requirements for producing the commodity in the local environment). 

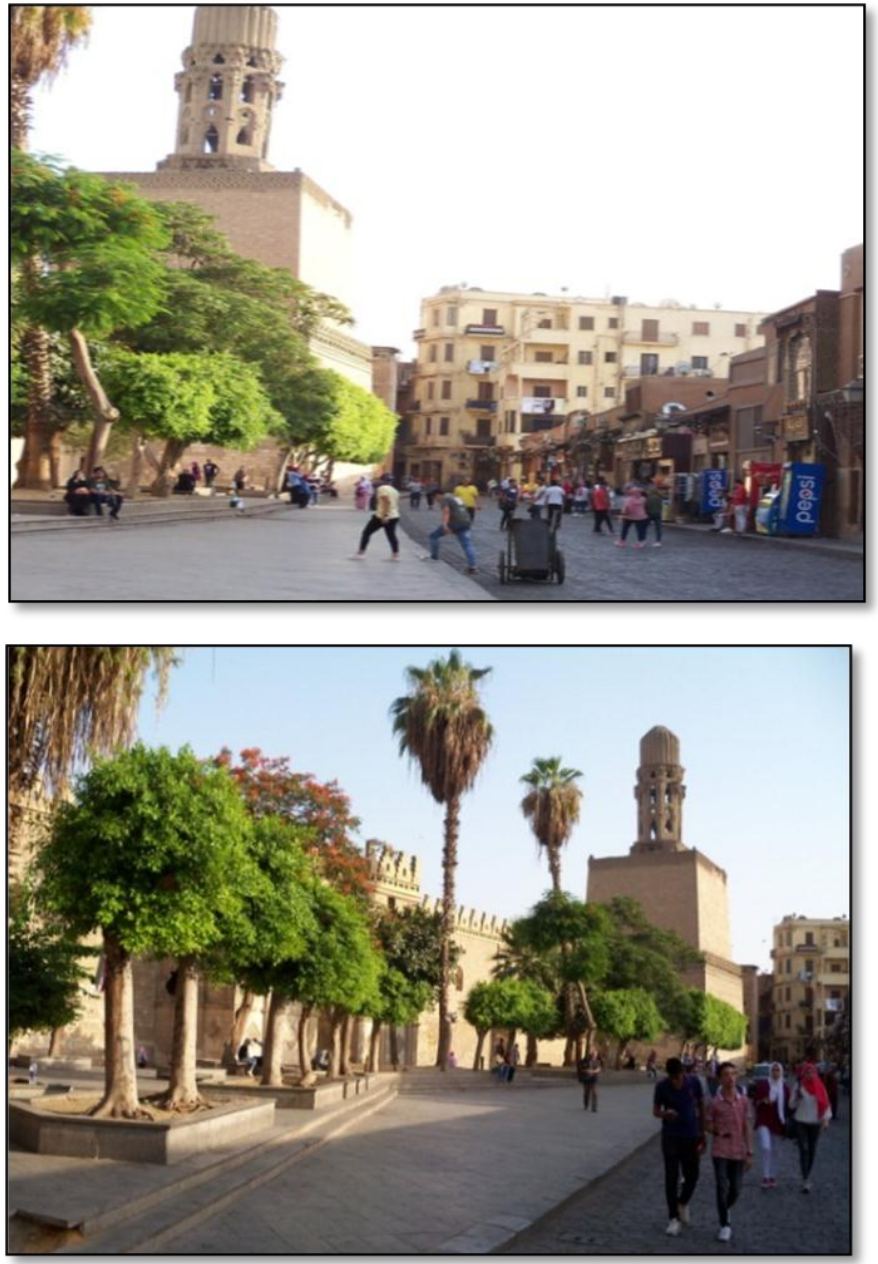

Figure 17: the emptiness in front of the Al-Hakim Bi'amr Allah mosque on Al- Maezi Lidin Allah Alfatma Street in historical Cairo [7].

5. Markets are connected to local production from simple industries (simple craft workshops), as it was in previous times Before the manufacturer separ21ated from the market (after the industrial revolution), The old mode fits into social marketing trends. The tangible markets were like an open exhibition where the shopper enjoyed learning about the ways to manufacture the commodity. This is suitable for simple industries that do not require a lot of equipment. It is suggested that the shopper be allowed to participate in manufacturing if possible (workshops held in the fields of activity that the research is looking to add to the market). For the shoppers will enjoy the activity and feel the importance of the commodity. This results in the substitution of the imported goods for a local good. It also indirectly directs employment and individuals in society to industries and projects that have the potential to be built in their country. These workshops also repair damaged goods with the shopper so that they can play their role instead of consuming new goods. As seemed in (Figure 18).

6. The classic condition theory ${ }^{[a]}$ of modifying human behavior is applied. The proposed development activity that is added to the market is mixed with an existing activity that attracts the shopper, especially in the beginning stage of mixing the developmental activities with shopping. The two activities are linked together in the shopper's mind to the activity.The shopper is attracted to the new activity out of his love for the original activity. The development activity is mixed with the entertainment elements or cafeterias and restaurants that are clearly present in the Egyptian market. Where the activity of recreation and entertainment (32.1\%), then eating and drinking (25.7\%) among the study sample members, was an important reason for hesitation in non-stores. The group that frequented non-stores in the markets at a high medium and medium rate chose the reason for entertainment and entertainment to hesitate on the market. The shopping pleasure of the study sample was related to a direct relationship with entertainment and walking.

[a] Classical Conditioning Theory: The behavior to be confirmed is associated with enjoyable activities for the individual, So the individual has an emotional response to the love of the desired behavior,

The correlation between the conditional stimulus and the conditional response is strengthened by repeatedly pairing them together. This pairing is considered a reinforcement of the conditional stimulus to be confirmed. After a period of discontinuation of the stimulus and the response, the non-enhanced police response turns off for a period of time during which the individual relaxes. Then the policewoman reappears again, individually. This is known as automatic retrieval [21].

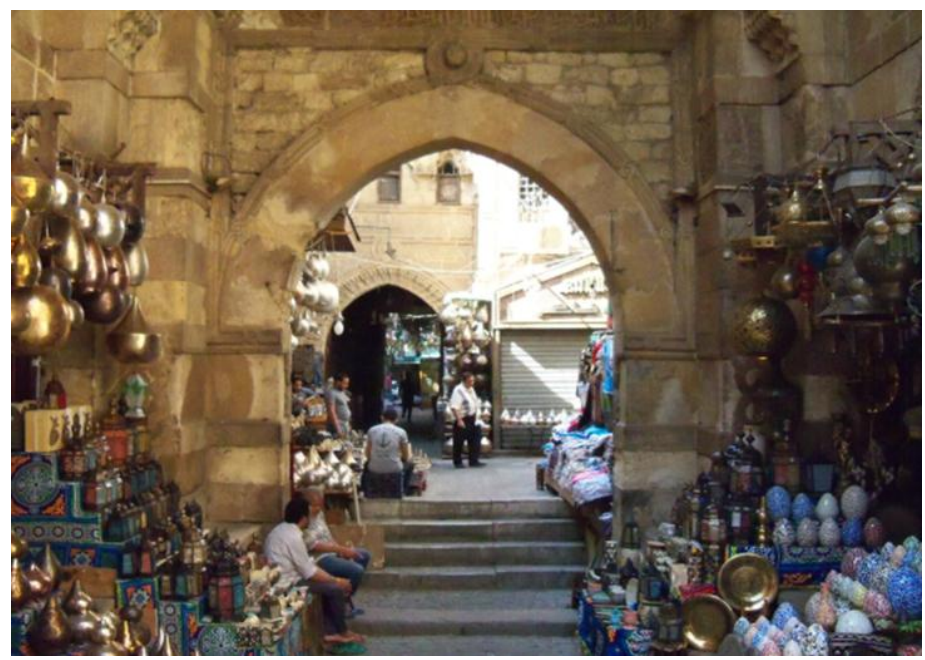

Figure 18: The return of simple artisan activity in the Egyptian market instead of its transformation into a commodity exhibition (Khan AlKhalili in Historic Cairo)[7].

7. Group activities are established with market spaces to suit family members of all ages to attract everyone. It takes an extensive search for activities that are able to attract shoppers depending on the style of each market and the target shoppers category.

The researcher observed the classification of the Egyptian shopper into two classes, the first class has ready to participate in group activity and interact with others. The second class will be difficult to attract to interact with the accompanying activity. As seemed in (Table 10). 
Table 10: Categories of Egyptian shoppers were classified according to their personality and their willingness to socialize in places of doing trade [7].

\begin{tabular}{c}
\hline Personal shopper \\
\hline Activity pattern \\
\\
Proposed modeling \\
method to start with \\
interactions with \\
developmental \\
activity
\end{tabular}

Shopper goes to the market for

Shopper goes to the market with

Gender Age

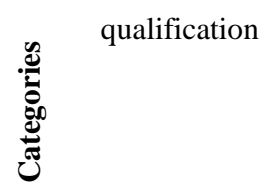

Income

Social status

You are on the market

Frequency of noncommercial elements

-Participation Modeling
Live Modeling

Social communication, fun shopping, entertainment and strolling

Other shoppers, (friends or family)

Female

The young age group (especially 21-30) People with the least
qualification

Income more than 10,000 or less income group, especially a group without income and income group less than 2000

The status of marital status is not married or a child

\section{4: 5 hours or $2: 3$ hours}

Medium then above medium and high.

The shopper feels comfortable and familiar with the markets at a rate

The frequency is affected by

Medium then above medium and high

Time and need for the goods

Little time or no

The shortest possible period

Do not deal or medium then less than medium

\section{Medium} desire

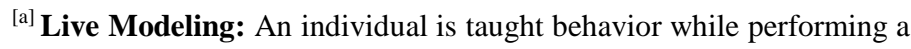
skill with a person next to an educated individual.

x Participation Modeling: The model and the individual share the skill performance at the same time, and the modeling process may accompany participation to provide an enhancement of the individual's performance of the required skill.

x Symbolic Modeling: The behavior to be modeled is shown by films and illustrated materials. Pictures were displayed in a manner that revealed the steps to perform the behavior.

× Self as a Model: A complete explanation about the behavior is provided. Then the individual is required to perform the behavior, and the learner is recorded while performing the behavior. The registration is re-presented to the individual while promoting effective performance. Then the individual is asked to apply the modeled behavior to the actual situations [21].

\subsection{The end result}

1. The position of trade activities in Egypt is not compatible with the social orientation of marketing.

2. The activities associated with shopping in the Egyptian market were limited to the activities of (cafeterias- children's games - cinema...) urging the shopper to support the culture of consumption and not develop his/ her skills.

3. The study sample members missed the attractions during their trip in the Egyptian markets. The reason for choosing the number of frequencies on the market was justified to the need pattern $(49.5 \%$ of the study sample) and the average time available ( $7.5 \%$ of the study sample).

This was confirmed by the bias of a number of the sample to spend from two to three hours only (40 $4 \%$ of the study sample) on the shopping trip. Most of the sample was attracted to the frequency on the non-trade elements with an average rate $(42.2 \%)$ and then a rate below the average (38.5\%). The sample attributed the reason for the frequency of the non-stores to entertainment and entertainment (32.3\%). As seemed in (Figure 13).

4. The research observed the satisfaction of the study sample for the situation of the Egyptian markets with which it deals. The study sample felt comfortable and affliction within the markets at an average rate ( $45 \%$ of the study sample), then an above average rate $(21.1 \%$ of the study sample), and then a high rate ( $15.6 \%$ from the study sample). This means that the Egyptian shopper is not aware of the social role of markets, as well as the possibility of developing members of society through places of trade activity because of the persistence of their reluctance and relative acceptance of them. As seemed in (Figure 13).

5. The researcher observed the classification of the Egyptian shopper into two classes, one that goes for the pleasure of shopping, entertainment and strolling in the market, the shopper usually goes with other shoppers, especially friends or family. This group has ready to participate in group activity and interact with others. The second class does not like dealing with markets except in the narrowest limits, and this will be difficult to attract to interact with the accompanying activity.

6. The focus of the vacation period is on activities suitable for the younger age group under 20 or 21-30 years and the intermediate qualification category. It is a category that does not hesitate to market, except for holidays only, or once every more than two weeks.

\subsection{Recommendation}

The research is recommended profit from the Egyptian traditional culture to increase the human interaction in the markets, and to support the accompanying interactive 
development activities in the Egyptian urban markets. In an image that is appropriate to the correct path of social marketing. The matter needs:

1. It is recommended to search for the type of development activities appropriate to attract each societal group of Egyptian shoppers and suitable for each region according to the characteristics of the productive area and the available development resources. The patterns of activities appropriate to each market will be reached according to the target shoppers' category and the features and capabilities of the market area.

2. The pattern of accompanying activities is diversified continuously. The shopper's activity are guided by the requirements of the available labor market or the shopper's learning and develops his/ her personal skills in a manner that reduces his/ her dependence relatively on manufactured goods.

3. It is proposed to change the accompanying activities at a rate of once every more than two weeks $(26.6 \%$ of the total sample is hesitant on the market at a rate of once every more than two weeks), and from 1: 2 once a week (30.3\% of the total sample is hesitant to the market at a rate of 1: 2 once a week) in important markets where the shopper frequency increases or the markets that are attended by highly qualified people. The shopper feels the change every time he comes to the market, so the accompanying activity will be one of the most important elements of excitement and attraction of the shopper.

4. It is recommended to research the exploitation of heritage buildings and legacies as part of the accompanying activity in the market. This confirms the identity of the place, develops the feeling of belonging to the shopper, and brings life to the legacies. In most of the legacies, there are external courtyards or inner courtyards that allow the practice of development activities.

5. Trade buildings are constructed in Al Wikalat and Al Rubue in the Islamic era, Shops specialize in a specific good, and the middle courtyard is used to serve the proposed accompanying activity.

6. The government's support for micro, small and medium enterprises and industries. Places are created for them on the market and are highlighted on creators and artists. Small and medium enterprises play an economic and social role (absorption of unemployment - increased production).

7. The one day market is chance to add some cultural activities with selling places such as art galleries, the presence of crafts. Showing their abilities small which encourages the value of production to support small productive business in the society.

8. It is proposed to develop a complete detailed marketing plan that supports the spread of the idea of the activity accompanying the Egyptian market. The plan includes details of all stages of activity creation and spread in the markets (study- preparation - implementation - development- follow- up and evaluation..) and identifies the bodies that are responsible for following up and implementing the plan.

\section{References}

[1] KABILA FARIS HMOOD, "TRADITIONAL MARKETS IN ISLAMIC ARCHITECTURE: SUCCESSFUL PAST EXPERIENCES", Structural Studies, Repairs and Maintenance of Heritage Architecture XV, www.witpress.com, WIT Transactions on The Built Environment, Vol 171, WIT Press, doi:10.2495/STR170231, 2017, P.263: 273

[2] Walaa Abou El-Haggag Mehanna, Wesam Abou El-Haggag Mehanna, "Urban renewal for traditional commercial streets atthe historical centers of cities", Alexandria Engineering Journal, Alexandria University, www.elsevier.com/locate/aej, 21 October 2019, p. 1127: 1143.

[3] William Pride\& Ferrell, "Marketing Concepts and Strategies", 12th ed, Houghton Mifflin Company, 2003, p. 11\&85.

[4] Mona Abaza, "Changing Consumer Cultures of Modern Egypt Cairo's Urban Reshaping", Social, Economic and Political Studies of the Middle East and Asia (S.E.P.S.M.E.A.), VOLUME 101, Library of Congress Cataloging, BRILL, Koninklijke Brill NV, Leiden, The Netherlands, 2006. P.3, 28, 168.

[5] Essam Mohamed Salah El Din, "Approach Towards The Development Of Planning And Design Of Commercial Centers In Light Of The Impact Of Information And Communications Technology", Ph.D., Unpublished, Architecture Dept., Faculty of Engineering, University of Cairo, 2012, P. 124\& 130.

[6] Ieva Andersone, Elina Gaile-Sarkane, "BEHAVIORAL DIFFERENCES IN CONSUMER PURCHASING BEHAVIOR BETWEEN ONLINE AND TRADITIONAL SHOPPING: CASE OF LATVIA", ECONOMICS \& MANAGEMENT, ResearchGate, 2009. 14, P. 345: 352

[7] Authors

[8] R. Craig Lefebvre, (2011),"An integrative model for social marketing", Journal of Social Marketing, Vol. 1, Iss: 1 pp. 54 - 72

[9] Alaa Farhan Talib et al., "Green Marketing Philosophy", first edition, Dar Safaa for Publishing and Distribution, Amman, Jordan, 2010, P. 115 \&119.

[10] Murlidhar Ananda Lokhande, Babasaheb Ambedkar, "Social Marketing", Indian Journal of Marketing, ResearchGate, March 2003. P. 16: 18.

[11] Peter Ferdinand Drucker, "The Practice of Management", Harper \& Row, HarperCollins Publishers, 1954, P. 20

[12] Robert F. Lusch1 and Frederick E. Webster Jr, "A Stakeholder-Unifying, Cocreation Philosophy for Marketing", Journal of Macromarketing, 31(2), 2011, P.129: 134

[13] WWW.Buseco.com, 2007, p. 1.

[14] Philip Kotler\& Gary Armstrong, "Marketing An Introduction", 5th ed, Pearson Education, Inc, 2000, p.18, 557

[15] Quentin Pickard, "The architects' handbook", Blackwell Publishing Company, USA, Reprinted 2003, p.335,340

[16] https://www.5plusdesign.com/architecture/cairo-festival-city, 2016

[17] Ala'Eddin Mohammad Khalaf Ahmad, "Attractiveness Factors Influencing Shoppers' Satisfaction, Loyalty, and Word of Mouth: An Empirical Investigation of Saudi Arabia Shopping Malls", International Journal of Business Administration, Vol. 3, No. 6; 2012 http://dx.doi.org/10.5430/ijba.v3n6p101, Sciedu Press, www.sciedu.ca/ijba, November 9, 2012, P. 101: 112

[18] Patrick Schober, Christa Boer, and Lothar A. Schwarte, "Correlation Coefficients: Appropriate Use and Interpretation", ANESTHESIA \& ANALGESIA, volume 126, Number 5, SPECIAL ARTICLE, www.anesthesiaanalgesia.org, 2018, p.1763: 1768

[19] https://www.statisticshowto.datasciencecentral.com/spearman-rankcorrelation-definition-calculatel

[20] SPSS Exact Tests ${ }^{\mathrm{TM}} 7.0$ for Windows $\square$ Cyrus $R$. Mehta and Nitin $R$. Patel/SPSS Inc. United States of America, 1996, p. 15

[21] Usama Faruk Mostafa, " Modification and construction of human Behavior Normal \& Abnormal", Egyptian Anglo eBook, Egypt, 2017, P. 11 \& 36 \& 152. 